\title{
Label-free, simultaneous quantification of starch, protein and triacylglycerol in single microalgal cells
}

Yuehui He ${ }^{1,2+}$, Peng Zhang ${ }^{1,2+}$, Shi Huang ${ }^{1,2}$, Tingting Wang ${ }^{1,2}$, Yuetong Ji ${ }^{1,2}$ and Jian $\mathrm{Xu}^{1,2,3^{*}}$ (D)

\begin{abstract}
Background: Current approaches for quantification of major energy-storage forms in microalgae, including starch, protein and lipids, generally require cell cultivation to collect biomass followed by tedious and time-consuming analytical procedures. Thus, label-free, non-destructive and simultaneous quantification of such macromolecules at single-cell resolution is highly desirable in microalgal feedstock development and bioprocess control.

Results: Here, we established a method based on single-cell Raman spectra (SCRS) that simultaneously quantifies the contents of starch, protein, triacylglycerol (TAG) and lipid unsaturation degree in individual Chlamydomonas reinhardtii cells. Measurement accuracy for the contents based on full SCRS spectrum each reached 96.86-99.24\%, all significantly higher than single peak-based models. However, accuracy and reliability of measurement are dependent on the number of cells sampled, thus a formal mathematical framework was proposed and validated to rationally define "minimal sampling depth" for a given state of cellular population. Furthermore, a barcode consisting of 13 marker Raman peaks was proposed to characterize the temporal dynamics of these energy-storage products, which revealed that the average contents of starch and TAG increased, while their heterogeneity indices decreased, with those of protein being exactly the opposite. Finally, our method is widely applicable, as measurements among cells from liquid suspension culture, wet paste and frozen dried powder all exhibited excellent consistency.
\end{abstract}

Conclusions: When sampled at proper depth, SCRS can serve as a quantitative and generally applicable tool for characterization and screening of strains and bioprocesses based on the profile of energy-storage macromolecules and their among-cell heterogeneity.

Keywords: Single-cell Raman spectroscopy, Starch content, Protein content, Triacylglycerol content, Phenotypic heterogeneity, Sampling depth, Chlamydomonas reinhardtii, Microalgae

\section{Background}

The co-existence of multiple intracellular energy-storage forms and the interconversion among them are a common theme of microbial, plant or animal cells on Earth. For example, microalgae, a huge and diverse group of

\footnotetext{
*Correspondence: xujian@qibebt.ac.cn

${ }^{\dagger}$ Yuehui He and Peng Zhang contributed equally to this work

${ }^{1}$ Single-Cell Center, CAS Key Laboratory of Biofuels and Shandong Key Laboratory of Energy Genetics, Qingdao Institute of BioEnergy and Bioprocess Technology, Chinese Academy of Sciences, Qingdao, Shandong, China

Full list of author information is available at the end of the article
}

unicellular plants, can efficiently convert solar energy and carbon dioxide into a variety of co-present intracellular energy-dense macromolecules, which mainly include polysaccharides (e.g., starch), proteins and lipids (e.g., triacylglycerol, TAG) [1-3]. Thus, the ability to simultaneously measure the cellular contents of these compounds with high throughput and low cost is of value to strain development, process engineering and mechanistic studies of cell factories.

However, current approaches for profiling starch, protein and TAG contents in microalgae and plant cells generally consist of multiple tedious and time-consuming 
steps, including accumulation of biomass, extraction of metabolite mixtures from the bulk biomass and then quantification of the target compounds by separate assays. After the extraction of metabolite mixtures, the inherently inefficient "one procedure per target compound" paradigm was generally followed: (i) for starch, enzymatic conversion to glucose and then quantification by colorimetric analysis [4, 5]; (ii) for proteins, purification of proteins via alkaline lysis and then quantification by bicinchoninic acid-based spectrophotometric assays [6] and (iii) for TAG, conversion to fatty acid methyl esters (FAMEs) via transesterification and then quantification by gas chromatography-mass spectrometry (GCMS) [7]. Notably, due to the requirement for significant amounts of microalgal biomass (typically at the $\mu \mathrm{g}-\mathrm{mg}$ range) to start with, these approaches are dependent on a priori cultivation of cells. This limitation further slows down the analysis, hinders the increase of throughput and even renders the analysis impossible, as many or most of the microbial cells (including microalgae) in nature remain difficult to culture.

To tackle these challenges, single-cell-based methods for metabolite analysis have emerged [8,9]. For example, oligosaccharides and flavonoids in single yeast cells were successfully analyzed by mass spectrometry (MS) [10]. However, MS-based methods usually require destructive and sophisticated sample preparation which excludes downstream additional analysis of genomes or transcriptomes. On the other hand, fluorescent proteinbased sensors $[11,12]$ or aptamer-based technology [13, 14] were used to image proteins and nucleic acids such as calmodulin-binding peptides and ribozymes. However, these methods usually are applicable to only those cells that can be labeled and those metabolites that can be labeled quantitatively with fluorescence tags or aptamers. Clearly, single-cell technologies capable of simultaneously, rapidly and readily measuring starch, protein and TAG contents in a non-destructive, label-free and generally applicable manner are of great value.

Single-cell Raman spectra (SCRS) represent the collective Raman spectra of molecules in one cell and provide an intrinsic chemical profile of the cell in a label-free and non-destructive manner [15-17]. As each molecule carries characteristic Raman spectra, many studies have attempted to model the contents of certain molecules in an isogenic cell population based on a collection of SCRS randomly sampled from the population (also called a Ramanome; [18]). However, a number of key questions remain unanswered. (i) Most past studies have selected one or just a few Raman peaks (typically derived from Raman spectra of reference chemicals) for the quantification of target compounds, yet did not evaluate the reliability of such choices [19-21]. For example, the relative abundance of lipids, paramylon and chlorophyll in Euglena gracilis was estimated via 2850, 2910 and $2937 \mathrm{~cm}^{-1}$ [19], while that of lipids and astaxanthin in Haematococcus pluvialis was estimated via 1448 and $1520 \mathrm{~cm}^{-1}$ [20]; however, whether and to what degree these peaks can specifically quantify the target compounds were actually not assessed. (ii) Most studies that aimed for quantification only target one singular compound, such as the starch content in Chlamydomonas reinhardtii and Chlorella pyrenoidosa [22] or the TAG content in Nannochloropsis oceanica [23], yet it is not clear whether the cellular contents of the co-existent energy-storage compounds, e.g., starch, protein, TAG and others, can be simultaneously quantified. This is important as many factors including the potential overlaps of Raman bands assignment among compounds, choice of sample pre-treatment methods, parameters of Raman measurement and species-specific property of microalgae can all potentially limit the practicability and reliability of SCRS in generating the measurements in a quantitative and 'landscape-like' manner. (iii) To derive the overall content and its degree of variation for target molecules in a cellular population, most studies have either sampled cells at a very low sampling depth [24-26], i.e., the number of cells measured for SCRS (e.g., only three cells sampled from each population [24]), or have not provided any rationale for their choice of sampling depth [19, 22, 23, 27, 28]. In fact, the link between method performance and sample depth, an experimental parameter directly determining throughput and common to all SCRS-based experiments, has not been critically probed. (iv) Most studies have tested method performance on live single cells from suspended liquid cultures [21-24], and whether the method is robust under other frequently encountered storage conditions is not clear, which however can be a crucial limiting factor as living cells may be either unobtainable or of limited shelf live (thus, sample freezing might be inevitable before SCRS acquisition).

Here, by deep sampling the SCRS of $C$. reinhardtii at 16 time points over 8 days under nitrogen depletion, we established a method based on single-cell Raman spectra (SCRS) that simultaneously quantified the contents of starch, protein, triacylglycerol and lipid unsaturation degree in individual cells. The measurement accuracy for the contents based on full spectrum each reached 96.86$99.24 \%$, all significantly higher than single peak-based models. However, accuracy and reliability of measurement are dependent on the number of cells sampled, thus a formal mathematical framework was proposed and validated to rationally define "minimal sampling depth" for a given state of cellular population. Furthermore, a barcode consisting of 13 marker Raman peaks was 
proposed to characterize the temporal dynamics of these energy-storage products, where the average contents of starch and TAG increased while their heterogeneity indices decreased, with those of protein being exactly the opposite. Finally, measurements among cells from liquid suspension culture, wet paste and frozen dried powder exhibited excellent consistency, suggesting applicability under a wide range of cell-storage conditions. Thus SCRS, when sampled at proper depth, can serve as a quantitative and generally applicable tool for the characterization and screening of strains and bioprocesses based on cellular biosynthetic profile and its among-cell heterogeneity.

\section{Results}

Dynamics of starch, protein and TAG contents and lipid unsaturation degree at the population level as measured by conventional approaches

To test whether the contents of starch, protein and TAG can be simultaneously quantified at the single-cell level via SCRS, the stress response process of $C$. reinhardtii under nitrogen depletion was employed as a model (Additional file 1: Figure S1a). To validate the new method, conventional approaches were separately used, via the aforementioned "one procedure per target compound" paradigm, to measure starch, protein and TAG contents based on metabolite mixture extracted from bulk microalgal biomass ("Methods"). The results revealed distinct temporal dynamics of these energy-storage compounds (Fig. 1a). Specifically, the starch content of the population increased by $>50$-fold, starting from $6.04 \pm 2.98 \mathrm{mg} / \mathrm{g}$ dry weight (DW) at $0 \mathrm{~h}$ to $323.58 \pm 7.78 \mathrm{mg} / \mathrm{g} \mathrm{DW}$ during Day 1, and then plateaued until a slight decrease to $284.79 \pm 2.98 \mathrm{mg} / \mathrm{g}$ DW at Day 8 . TAG content also increased (although to a much lower level than starch), from $1.20 \mathrm{mg} / \mathrm{g}$ DW at $0 \mathrm{~h}$ to the maximum of $35.0 \mathrm{mg} / \mathrm{g}$ DW at Day 6. However, the protein content sharply decreased from $565.90 \pm 11.67 \mathrm{mg} / \mathrm{g} \mathrm{DW}$ at $0 \mathrm{~h}$ to $225.86 \pm 13.15 \mathrm{mg} / \mathrm{g}$ DW at Day 2, and then gradually reduced to $160 \mathrm{mg} / \mathrm{g}$ DW during the next 6 days (Fig. 1a).

The change in neutral lipid content was validated by Nile Red staining under confocal fluorescence microscopy, which revealed that the number of lipid bodies in cells increased along the process (Additional file 2: Figure S2). Transmission electron microscopy further revealed that the number and average size of starch granules significantly increased during the process, while lipid bodies gradually emerged and then merged into larger ones (Additional file 3: Figure S3). Moreover, lipid unsaturation degree, as assessed by mass unsaturation ration $N_{\mathrm{C}=\mathrm{C}} / N_{\mathrm{CH} 2}$ of the mixed fatty acids in the cellular extract via gas chromatography-mass spectrometry (GCMS) analysis, underwent an increase from 1 to 8 days
(Additional file 4: Figure S4a). Thus during the 8 days, carbon storage mode of the cells had switched from a protein-central one to a starch-central one where TAG also made a contribution (albeit much smaller than starch).

\section{Simultaneous quantification of starch, protein, TAG contents and lipid unsaturation degree at the single-cell level via SCRS}

From the liquid suspension cultures that underlie the above analysis, SCRS from 60 randomly selected live cells were also collected ( 20 from each of three biological replicate cultures; Fig. 1b), at each of 16 time points over 8 days. Based on the reference chemical Raman spectra of pure starch, protein and TAG molecules, five Raman bands for starch, three for protein and five for TAG were proposed as the marker bands for quantification (Table 1). Their intensity, when averaged over all cells at a time point, exhibits positive correlation with the starch, protein and TAG contents measured via conventional approaches (correlation coefficient $R^{2}$ ranging from 0.6976 to 0.9300 for starch, from 0.7638 to 0.9105 for protein, and from 0.7721 to 0.8974 for TAG; Table 1). Moreover, the ratio of unsaturated-to-saturated carbon-carbon bonds, as measured by the relative intensity between the Raman bands of $1658 \mathrm{~cm}^{-1}$ (allyl C=C stretches proportional to the amount of unsaturated $\mathrm{C}=\mathrm{C}$ bonds) and $1441 \mathrm{~cm}^{-1}$ (Alkyl $\mathrm{C}-\mathrm{H}_{2}$ bend proportional to the amount of saturated $\mathrm{C}-\mathrm{C}$ bonds), was used to model the lipid unsaturation degree of the cells [27, 29]. Consistently, $I_{1658} / I_{1441}$ exhibits positive correlation with lipid unsaturation degrees measured by GC-MS $\left(R^{2}=0.9096\right)$ (Additional file 4: Figure S4b), which validated the ability of $I_{1658} / I_{1441}$ to model the unsaturation degree of total lipids.

On the other hand, to take advantage of the rich and comprehensive information content in the SCRS, a chemometric multivariate method called partial least square regression (PLSR) was employed for predicting starch, protein and TAG contents of individual cells based on the full spectra of SCRS. PLSR is a method for developing multivariate calibration models for testing the correlations between the investigated properties and spectroscopic data. The normalized fingerprint region $\left(393.8-1801.4 \mathrm{~cm}^{-1}\right)$ and the hydrocarbon region (2701.6-3051.6 $\mathrm{cm}^{-1}$ ) were extracted for PLSR modeling due to their richness in information content. For each time point, two of the triplicate cultures were used as training dataset and the remaining one as test dataset for model validation. For example, for starch content, the PLSR model was established using the averaged SCRS of 20 cells in a biological replicate and the corresponding starch content measured by the amyloglucosidase $/ \alpha-$ amylase method. 

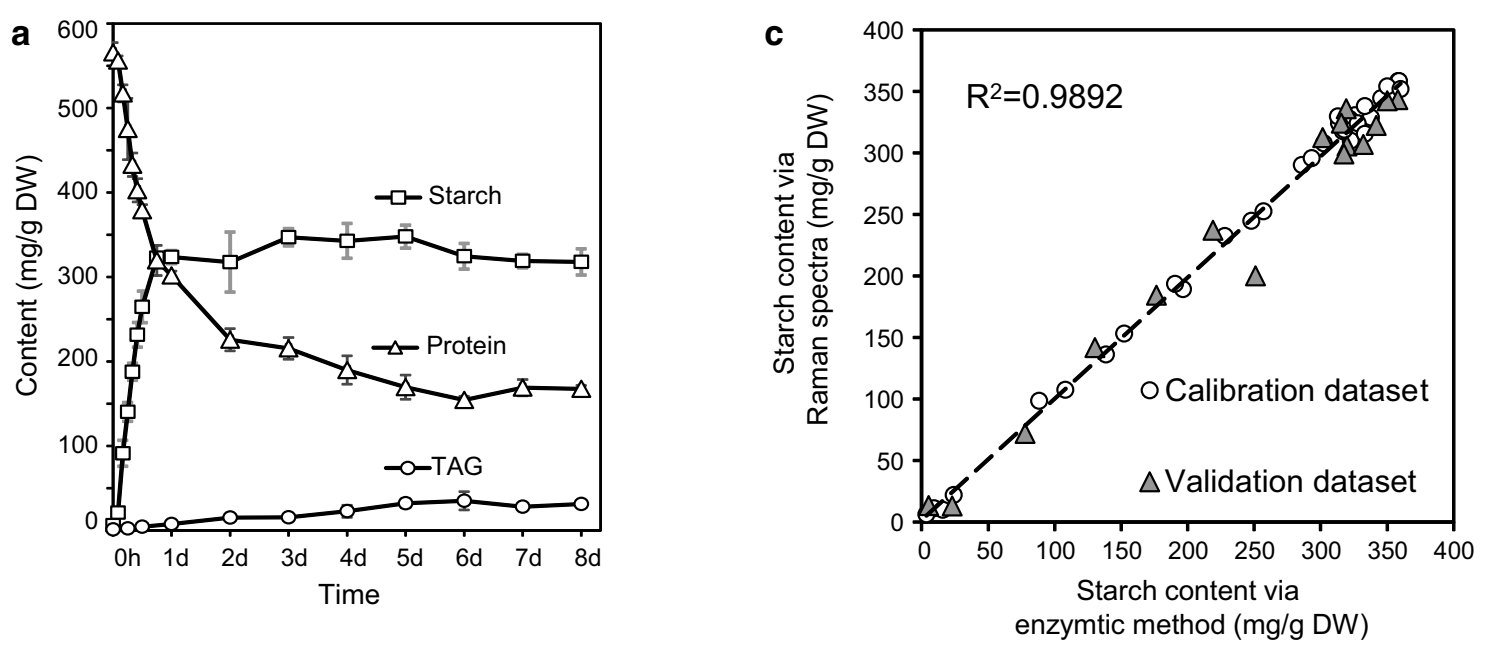

b
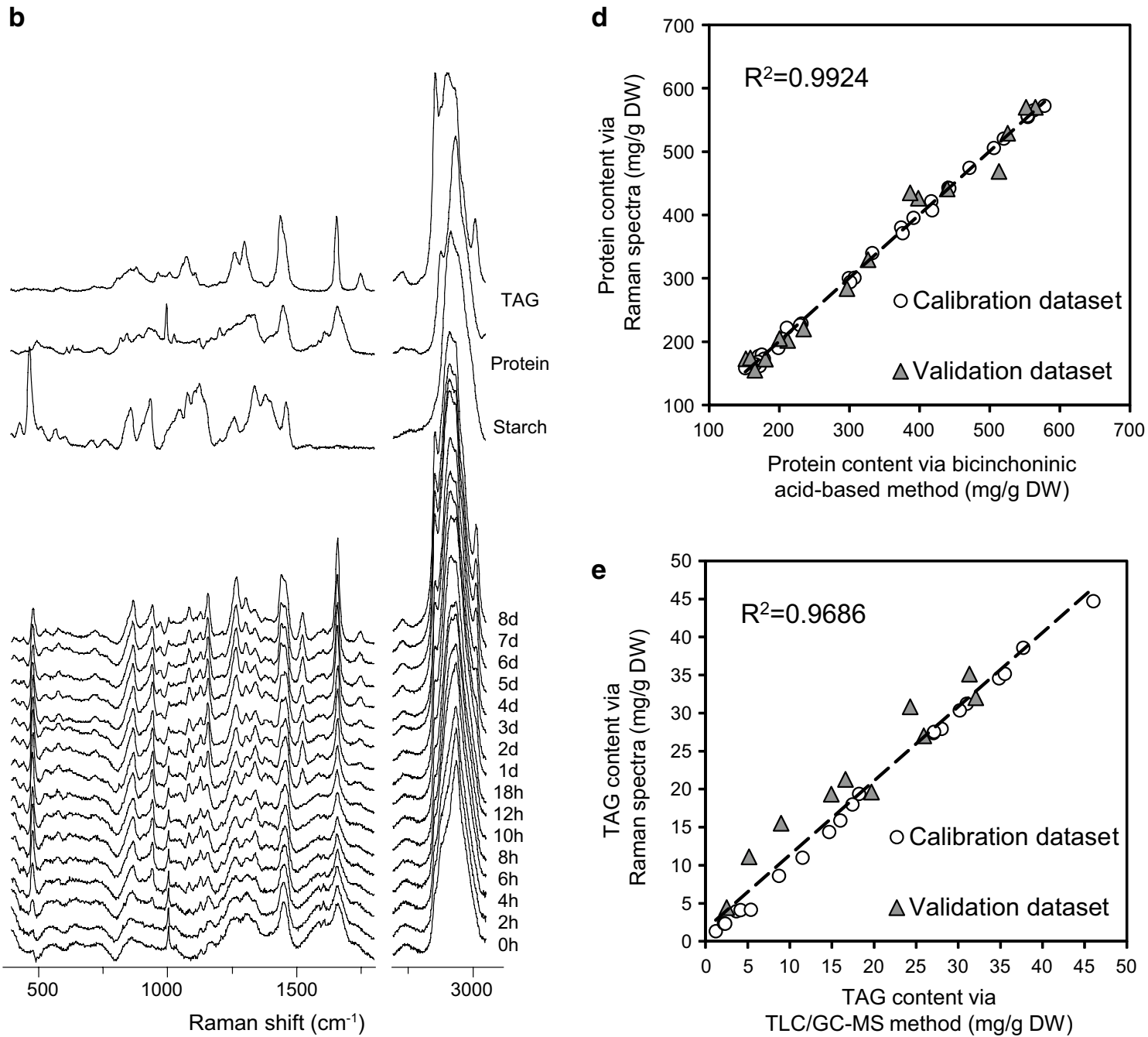
(See figure on previous page.)

Fig. 1 Quantification of starch, protein and TAG contents in individual Chlamydomonas reinhardtii cells via SCRS. a Dynamics of starch, protein and TAG contents in the bulk biomass as measured by conventional approaches. b Temporal alteration of the averaged SCRS sampled from 60 cells over three culture replicates at each time points along the 16 time points. Reference Raman spectra of starch (corn starch), protein (bovine serum albumin V) and TAG (triacylglycerol 48:3) are shown above the SCRS for comparison. The contents of starch (c), protein (d) and TAG (e) of individual cells were derived using PLSR models, and the averaged contents in the population ( $Y$ axis; two of the three culture replicates were used for calibration and one for validation) was plotted versus the corresponding value measured with conventional methods at the population level ( $X$ axis). PLSR: partial least square regression. TLC-GC-MS: Thin-layer chromatography coupled with gas chromatography-mass spectrometry. $R^{2}$ : correlation coefficient

The full spectrum-based PLSR model for starch content featured coefficient value $\left(R^{2}\right)$ of 0.9966 for the calibration dataset and 0.9766 for the validation dataset, with the overall coefficient value $\left(R^{2}\right)$ at 0.9892 , suggesting the high accuracy in modeling starch content in single cells (Fig. 1c). Similarly, the PLSR models for protein and TAG contents in single cells were built and validated, achieving overall $R^{2}$ of 0.9924 and 0.9686 , respectively (Fig. 1d, e). Each of the starch, protein and TAG contents derived via the full spectrum, when averaged from that of the individual cells as predicted by SCRS, was highly consistent with those experimentally determined from the bulk of microalgal biomass (Pearson correlation, $\rho=0.9984,0.9988$ and 0.9988 , respectively; $P<0.01$ ). Simultaneous visualization of the starch, protein and TAG contents of each of the 960 C. reinhardtii cells sampled over the 16 time points revealed the temporal landscape for microalgal energy storage compounds in the population at single-cell resolution (Fig. 2).

Collectively, these results underscore the advantages of full spectrum-based modeling of metabolite contents versus that based on the just a few marker Raman bands

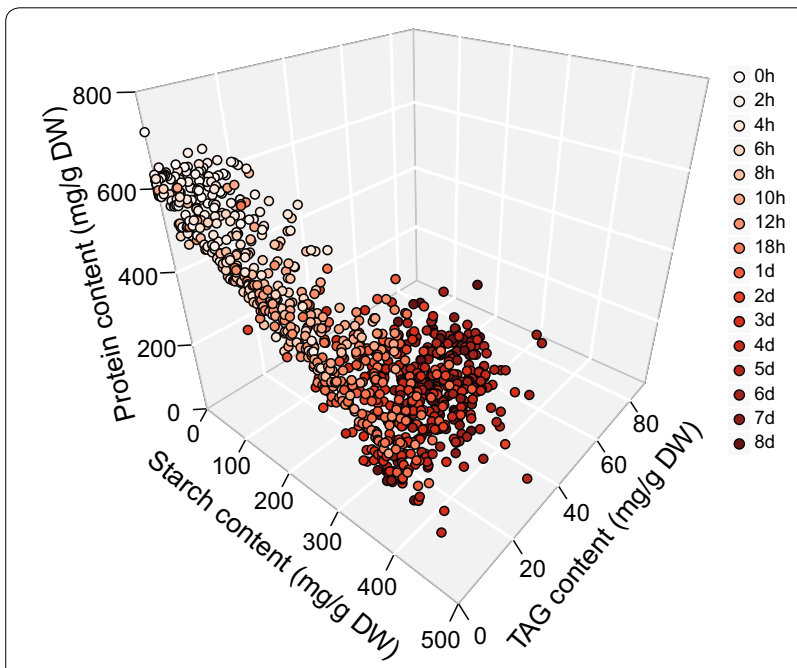

Fig. 2 Starch, protein and TAG contents of individual Chlamydomonas reinhardtii cells along the process of nitrogen depletion. Each data point represents one cell, with color indicating the time point when the SCRS was acquired
(Table 1), as it provides higher accuracy in measurement yet without replying on reference chemical spectra. Since they are generally applicable for $C$. reinhardtii $\mathrm{CC} 124$ cells, the datasets and scripts for building and validating the PLSR models can serve as valuable community resources (Additional file 5: Dataset S1, Additional file 6: Dataset S2, Additional file 7: Dataset S3, Additional file 8: Appendix S1). In conclusion, SCRS is able to simultaneously and accurately quantify starch, protein and TAG contents and lipid unsaturation degree at the single-cell level; moreover, the approach can be expanded to include other abundant metabolites in the cell.

\section{Heterogeneity of starch, protein, TAG contents and lipid unsaturation degree among individual cells}

The ability to model the four phenotypes at the single-cell level allows measurement of their degree of among-cell heterogeneity in a given population. The heterogeneity index (HI) of a quantitative phenotype or trait is defined as the RSD (relative standard deviation) of individual cells within the population. For each of the four phenotypes, the phenotypic frequency distribution indicated a high degree of heterogeneity in energy-storage compounds, which was prevalent in the C. reinhardtii population regardless of its state (Fig. 3a-c; Additional file 4: Figure S4c).

However, the temporal change of $\mathrm{HI}$ was quite distinct among the four phenotypes. For starch, while the average content was increased, HI decreased sharply during Day 1 and then stayed at the lowest level for the remaining 7 days (Fig. 3d). For protein, while the average content decreased, $\mathrm{HI}$ increased during the first $18 \mathrm{~h}$ and then stabilized for the next 7 days and was always much lower than HIs of starch or TAG at each time point (Fig. 3e). For TAG, HI exhibited a high level of fluctuation during the first $12 \mathrm{~h}$ and then decreased afterward (Fig. 3f). As for lipid unsaturation degree, the HI stayed largely stable at a relatively low level along the full course of observation (Additional file 4: Figure S4d).

\section{Sampling depth affects the accuracy of metabolite content and $\mathrm{HI}$ measurements}

Due to the inherent heterogeneity among cells in any population, phenotype measurements derived from 
Table 1 The 13 reference Raman bands that are highly correlated with starch, protein and TAG contents in Chlamydomonas reinhardtii $\mathrm{CC} 124$ during the process of nitrogen depletion

\begin{tabular}{|c|c|c|c|}
\hline Component & Raman bands $\left(\mathrm{cm}^{-1}\right)$ & $R^{2}$ & Assignments \\
\hline \multirow[t]{5}{*}{ Starch } & 478 & 0.6976 & $\mathrm{C}-\mathrm{C}-\mathrm{C}$ deformation \\
\hline & 865 & 0.9300 & $\mathrm{C}-\mathrm{C}-\mathrm{H}$ and $\mathrm{C}-\mathrm{O}-\mathrm{C}$ deformations \\
\hline & 940 & 0.8895 & $\mathrm{C}-\mathrm{O}$ stretching; $\mathrm{C}-\mathrm{O}-\mathrm{C}$ and $\mathrm{C}-\mathrm{O}-\mathrm{H}$ deformation; $\mathrm{a}-$ helix $\mathrm{C}-\mathrm{C}$ backbone \\
\hline & 1049 & 0.8308 & $\mathrm{C}-\mathrm{O}$ and $\mathrm{C}-\mathrm{C}$ stretching; $\mathrm{C}-\mathrm{O}-\mathrm{H}$ deformation \\
\hline & 1127 & 0.8862 & $\mathrm{C}-\mathrm{O}$ and $\mathrm{C}-\mathrm{C}$ stretching; $\mathrm{C}-\mathrm{O}-\mathrm{H}$ deformation \\
\hline \multirow[t]{3}{*}{ Protein } & 1003 & 0.7638 & Phenylalanine ring breath; carotene $\mathrm{C}-\mathrm{H}$ bending \\
\hline & 1586 & 0.9105 & Phenylalanine \\
\hline & 1610 & 0.8850 & $\mathrm{C}=\mathrm{O}$ stretching of protein amide $\mathrm{l} ;-\mathrm{NH}_{2}$ \\
\hline \multirow[t]{5}{*}{ Triacylglycerol $^{a}$} & 972 & 0.8438 & $v(C-C)$ wagging \\
\hline & 1265 & 0.8783 & $\mathrm{~A}|\mathrm{ky}|=\mathrm{C}-\mathrm{H}$ \\
\hline & 1441 & 0.8974 & Alkyl $\mathrm{C}-\mathrm{H}_{2}$ bend \\
\hline & 1658 & 0.7721 & Allyl $C=C$ stretches \\
\hline & 2851 & 0.8902 & $\mathrm{C}-\mathrm{H}_{2}, \mathrm{C}-\mathrm{H}_{3}$ asymmetric and symmetric stretches \\
\hline
\end{tabular}

Correlation coefficient $\left(R^{2}\right)$ between averaged intensity of the Raman bands derived from SCRS and the corresponding quantitative trait shown

a Correlation coefficients calculated based on post- $1 \mathrm{~d}$ datasets, since the TAG content of $C$. reinhardtii cells during the first day of nitrogen depletion was very low

SCRS might be potentially affected by the depth of sampling. Yet, the link between the accuracy of measurement and sampling depth remains untested. To quantitatively evaluate the observed diversity of SCRS at a particular sampling depth, a series of concepts were introduced. Briefly, (i) the Euclidian distance between any pair of SCRS sampled from a given population was used to measure the degree of divergence between the two SCRS; (ii) diversity index (DI), i.e., the maximal Euclidian distance among the set of SCRS sampled from a cellular population, was proposed to quantify the observed diversity of SCRS; (iii) cumulative DI is defined as the mean of the DI from a number of $(N=1000$ here) simulated sampling trials. In the end, a saturation analysis plot was devised that depicts the relationship between cumulative DI and sampling depth, so as to provide a theoretical basis for rational assessment and selection of sampling depth (Fig. 4a, b).

First, we assembled a virtual pool of SCRS consisting of all the 960 SCRS collected over the 16 time points starting from the onset of nitrogen depletion, which presumably includes all possible SCRS for the $C$. reinhardtii strain under the given culture condition. The observations of DI over 1000 in silico trials of SCRS acquisition from this virtual pool of SCRS were compared over each sampling depth, which ranged from 2 to 960 (Fig. 4a). The results revealed that the higher the sample depth, the closer is the cumulative DI to the full SCRS diversity in the population (i.e., the more completeness in sampling the SCRS diversity); however at and after a certain threshold of sample depth, the cumulative DI would reach saturation where the SCRS diversity sampled no longer further increases. For this virtual dataset of 960 cells, the sampling depth required to reach $90 \%$ of the full SCRS diversity sampled is 234 cells, which is termed the "safest sampling depth" for a given strain under a particular culture condition. Moreover, the choice of sampling depth greatly affects the cumulative DI and thus the degree to which the acquired SCRS collection captures the full diversity of SCRS: for example, at the sample depth of 3, 20 and 60 cells, the cumulative DI is 2.12, 3.46 and 3.91, which correspond to 43,70 and $80 \%$ of the theoretical maximal diversity of SCRS sampled (i.e., 4.91) (inset of Fig. 4a). On the other hand, in reality, one might never be able to thoroughly and exhaustively sample the SCRS space of a given isogenic cell population. Even for the 960-cell SCRS collection pooled from 16 time points here, the total SCRS diversity captured is still just an approximation of the "full" diversity. In fact, it is possible that no upper bounds are present for certain populations. Therefore, a definition of a "minimal sampling depth" that is not dependent on the total number of cells actually sampled is also valuable. To quantitatively determine whether the cumulative DI of an SCRS collection is saturated at a certain sampling depth, a term called "rate of cumulative DI" is defined, which measures the degree of cumulative DI increase with stepwise elevation of sampling depth ("Methods"). The parameter of "minimal sampling depth" is thus designated as the sampling depth at a cutoff of $1 \%$ for rate of cumulative DI, i.e., at this particular sampling depth, no more than $1 \%$ of increase in cumulative DI will be gained by sampling one more cell ("Methods"). The "minimal sampling depth" of the 960cell collection is 25 (Additional file 9: Figure S5a), which is, not surprisingly, much lower than the "safest sampling depth" of 234. 

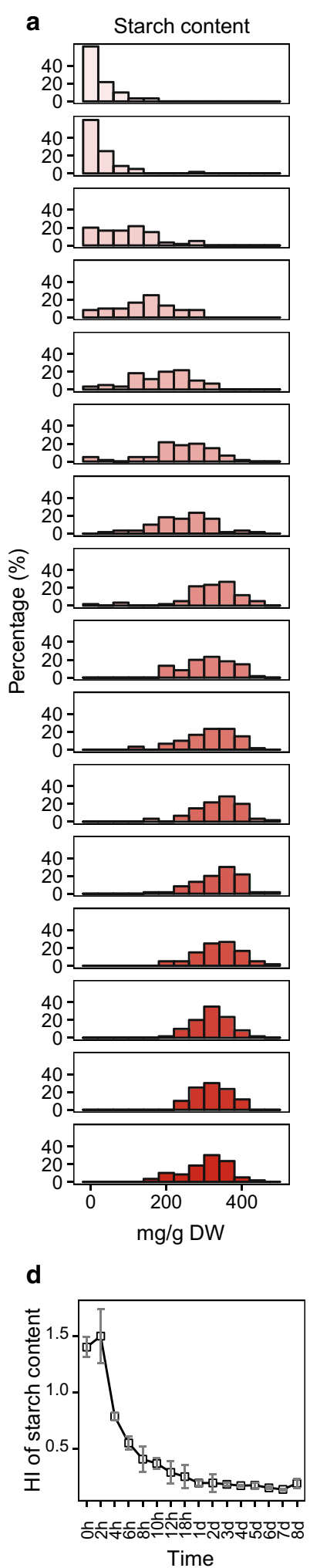

b
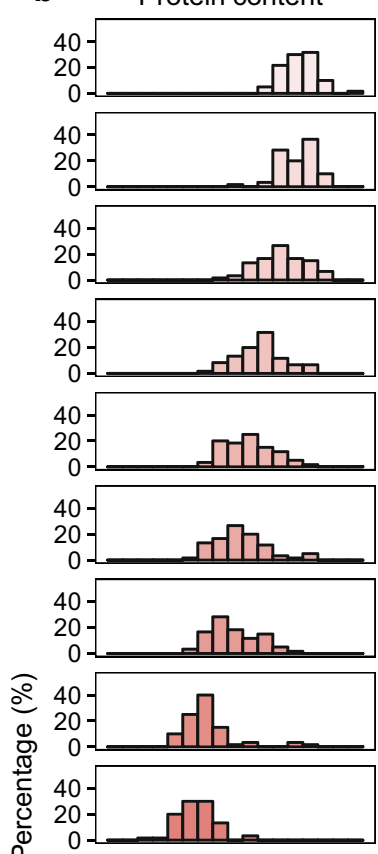

๑)
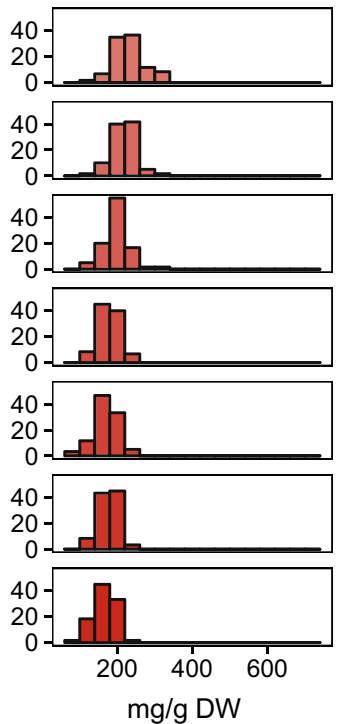

e

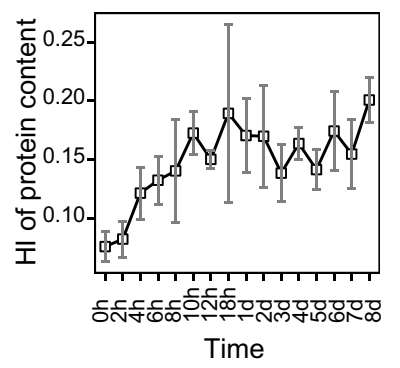

C TAG content
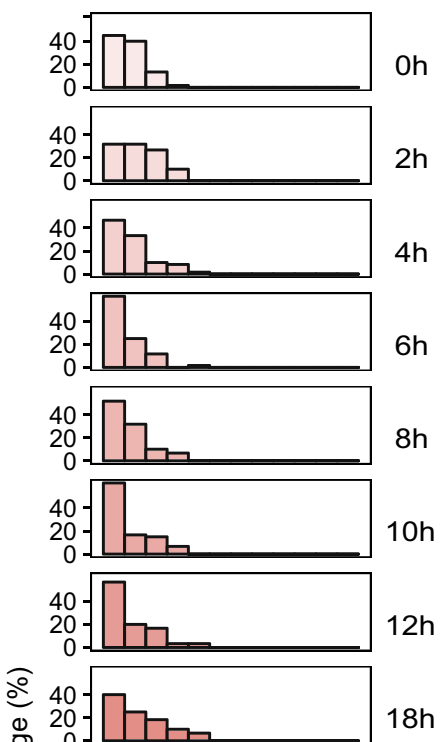

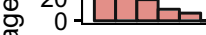

एँ. 40

仓ั. 20

$1 d$
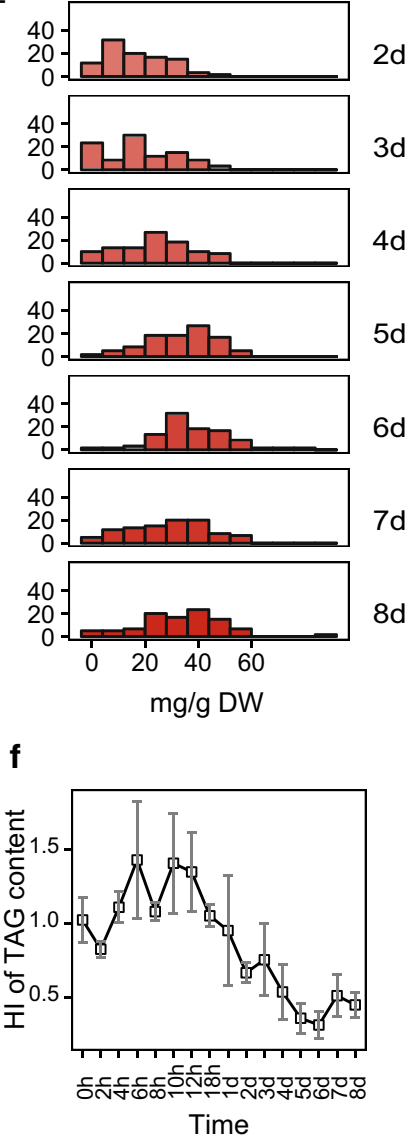

Fig. 3 Phenotypic heterogeneity within the Chlamydomonas reinhardtii populations. a-c Distribution of single-cell starch, protein and TAG contents in the population at each of the 16 time points. $X$ axis is the predicted starch, protein or TAG content in a cell (mg/g DW) and $Y$ axis is the frequency (\%) of such cells. DW dry weight. d-f Heterogeneity index (HI, i.e., relative standard deviation, RSD) of starch, protein or TAG contents in the populations at each of the 16 time points. Error bars represent the standard deviation from three biological replicates of culture at each time point 


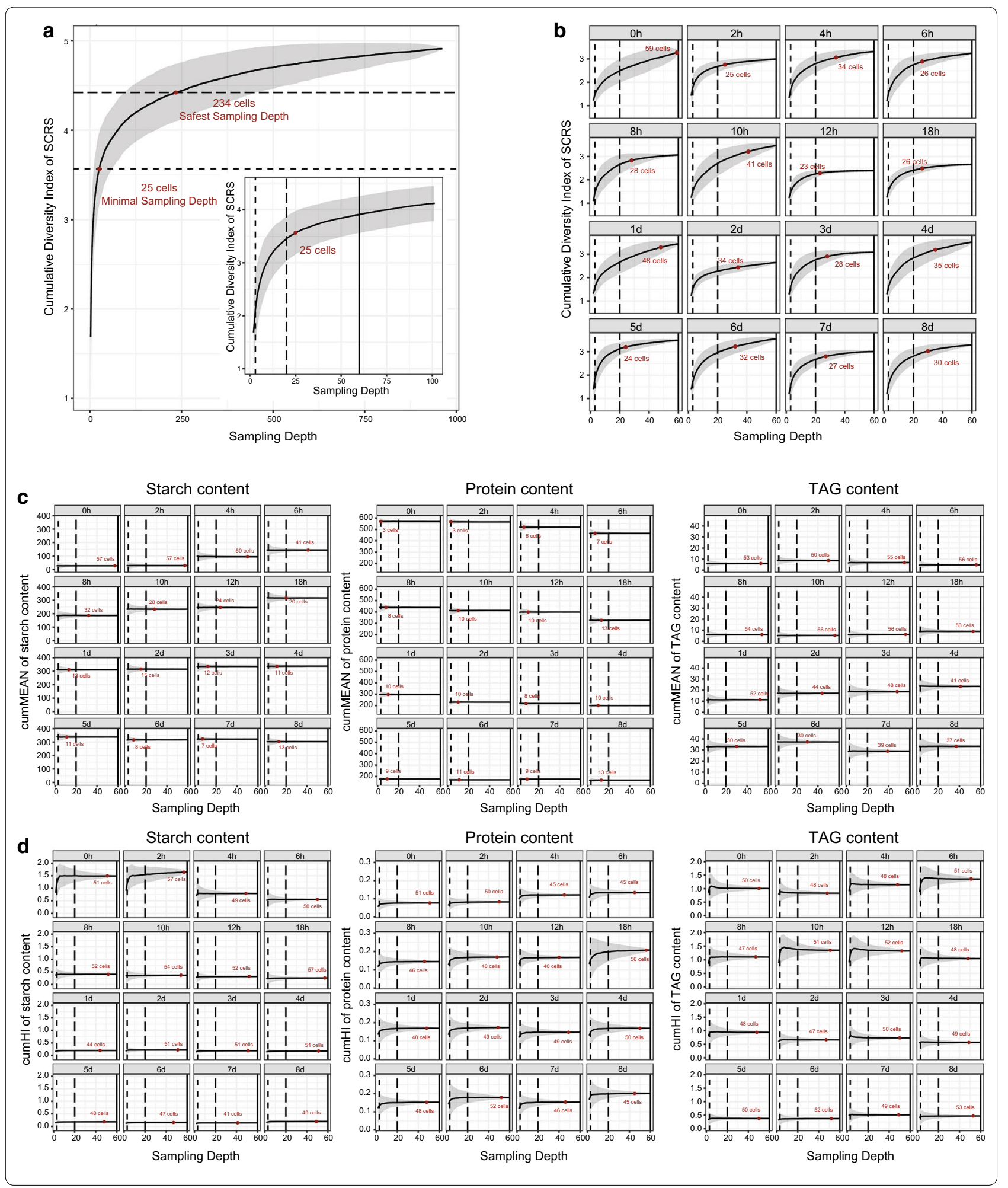


(See figure on previous page.)

Fig. 4 Effect of sampling depth on SCRS-based measurements. Quantitative relationship between sampling depth and the observed diversity of SCRS for an in silico population that includes all the cells sampled for SCRS over the 16 time points (a) or for the actual populations sampled for SCRS at each time point (b). At each sampling depth, 1000 permutations of sampling trials were performed, and the mean and standard deviations of the cumulative diversity index (DI) were calculated to estimate the extent to which the diversity of SCRS was observed and variation of the observation. In addition, quantitative relationship between sampling depth and the population average measurements of single-cell quantitative traits (c) and of their heterogeneity (d) is shown. Similarly, at each sampling depth, 1000 permutations of sampling trials were performed, and the cumMean and cumHI were calculated to estimate the observed values of quantitative traits and the variation of such observations. Gray areas represent the standard deviation of such measurements from the 1000 trials. The sampling depths of 3, 20 and 60 cells, each highlighted by a vertical line, were used as examples to quantitatively assess how the choice of sampling depth affects the accuracy and reliability of measuring the traits. For $\mathbf{a}$ and $\mathbf{b}$, the minimal sampling depth, defined as the depth when no more than $1 \%$ of gain in cumulative DI will be gained by sampling one more cell ("Methods"; Additional file 9: Figure S5a, S5b), is highlighted for the 960-cell virtual population and for each time point. For c and d, the minimal sampling depth, defined based on the boundary condition of deviation of no more than $5 \%$ from the true means or true $\mathrm{HI}$ of metabolite contents ("Methods"; Additional file 9: Figure S5c, S5d), is highlighted for each time point. Minimal sampling depth was highlighted with red point and the corresponding text

The 960-cell virtual pool of SCRS consists of cells from 16 distinct time points; thus, it represents the theoretical upper limit of SCRS diversity for a strain under a particular condition. In practice, a cellular population sampled for SCRS at a particular time point may represent only a subset of the 960-cell SCRS pool. To test whether and how the relationship between the observed SCRS diversity and sampling depth changes over the various time points, the observations of DI over 1000 in silico trials of SCRS acquisition from each of the 16 time points were compared over each sampling depth (from 2 to 60; Fig. 4b). The results revealed that sampling depth can greatly affect cumulative DI. For example, at the sampling depth of 3, the observed cumulative DI ranges from 1.44 to 1.84 , which are merely $45-62 \%$ (raised to $76-94 \%$ at the depth of 20 cells) of those at the depth of 60 cells. Thus, the sampling depth of 3 provides a highly incomplete and thus biased view of overall SCRS diversity at any of the time points, whereas in contrast the sampling depth of 20 or 60 cells yields a much better performance (Fig. 4b). Based on the definition above, the minimal sampling depth at each of the 16 time points was computed (Additional file 9: Figure S5b; also highlighted on Fig. 4b). They varied from 23 (at $12 \mathrm{~h}$ ) to 59 (at $0 \mathrm{~h}$ ), which suggested that the actual sampling depth of 60 in this experiment was sufficient at each of the time points.

For any quantitative trait at the single-cell level, assuming it follows normal distribution in an isogenic population, the mean and the degree of heterogeneity (or heterogeneity index; HI) are its most fundamental features. To provide a rational basis for determining the proper sampling depth of SCRS, we then tested the link between sampling depth and the measurements of mean and $\mathrm{HI}$ for the quantitative traits of interest. To test how the sampling depth influences the accuracy of measuring the metabolic contents and their respective $\mathrm{HI}$ for a given population state, we proposed the cumulative mean (cumMean) and cumulative HI (cumHI) as the observed mean and $\mathrm{HI}$ that were derived from 1000 in silico trials of SCRS acquisition at a particular sampling depth. At each of the trials, cells were randomly selected from the 60 cells at a certain sampling depth for SCRS acquisition, which were used to derive the mean and $\mathrm{HI}$ of quantitative traits (e.g., starch content, protein content and TAG content) as above. Their respective standard deviation errors over the 1000 trials (gray areas in Fig. 4c, d) were then computed to estimate the degree of variabilities in measurements of mean and HI.

For the measurement of population-averaged metabolite contents, at a low sampling depth, such as three cells per sample, for each of starch, protein and TAG under each of the 16 time points, experimental measurements of contents exhibit much higher variability than those at a higher sampling depth of 20 or 60 . Thus, the measurement at a sampling depth of three cells would be usually of low reliability, poor accuracy and can sometimes deviate from the actual mean (Fig. 4c). However, with the increase of the sampling depth, the measurements rapidly converge toward the actual mean and the standard deviation errors gradually turn lower (gray areas in Fig. 4c), which indicates that measurements of starch, protein and TAG contents would be of much higher accuracy and excellent reliability under higher sampling depth such as 20 or 60 cells. In fact, the minimal sampling depth for each of the three phenotypes at each of the time points was calculated, based on the boundary condition of deviation of no more than $5 \%$ from the true means of metabolite contents ("Methods"; Additional file 9: Figure S5c). Clearly, the minimal sampling depth is not only time point dependent, but phenotype specific: for protein content, they vary from $3(0,2 \mathrm{~h})$ to 13 (18 h, 8 days) (average of 9), while for starch content, they range from 7 to 57 (average of 25), with the time points before $18 \mathrm{~h}$ all higher than 20; in contrast, for TAG content, the values are generally even higher, ranging from 30 (5, 6 days) to $56(6,10,12 \mathrm{~h}$ ) (average of 47; Additional 
file 9: Figure S5c; also highlighted in Fig. 4c). Such variation originated from the distinct degrees of heterogeneity for the phenotypes.

For measurement of $\mathrm{HI}$ of the starch, protein and TAG contents, at a low sampling depth such as three cells per sample, the mean HI calculated from 1000 simulated experiments at most of the time points (in particular 0 and $2 \mathrm{~h}$ ) significantly deviated from the actual $\mathrm{HI}$, suggesting that $\mathrm{HI}$ measurements under low sampling depth would rarely be accurate at such a sampling depth (Fig. 4d). Moreover, under all the 16 time points, at a low sampling depth such as three cells per sample, the HI measurements show great variability, indicating the measurement results would be of low reliability and poor accuracy and likely deviating from the actual HI. However, with the increase of the sampling depth, the measurements rapidly converge toward the actual $\mathrm{HI}$ and the standard deviation errors gradually turn lower (gray areas in Fig. 4d), which indicates that measurement of the heterogeneity of metabolite contents is of much higher accuracy and excellent reliability under high sampling depth, such as 20 or 60 cells. Similar to the measurement of the mean content, the minimal sampling depth for each of the three $\mathrm{HI}$ at each of the time points was calculated ("Methods"; Additional file 9: Figure S5d). Interestingly, for each of starch, protein and TAG, the minimal sampling depth for $\mathrm{HI}$ are all within a narrow range of 40-57 (Additional file 9: Figure S5d; also highlighted in Fig. 4d). This suggests that to accurately profile the HI of a phenotype, generally higher minimal sampling depth is required.

In conclusion, the formal definition of sampling depth and the associated terms and saturation curves provide a theoretical basis for rational selection of proper sampling strategy for SCRS analysis. The simulation based on actual data proved that our strategy of sampling totally 60 SCRS (20 cells in each of triplicate cultures) at each time point provides an adequate coverage of the diversity of SCRS at the time point and thus yields accurate and reliable estimation of SCRS heterogeneity, as well as the content and $\mathrm{HI}$ measurements of starch, protein and TAG within a population.

\section{SCRS barcode for tracking the dynamics of the product profile}

To facilitate strain screening or bioprocess monitoring via SCRS, a signature barcode derived from SCRS was proposed that consisted of two panels, one for population-averaged traits and the other from the degree of among-cell heterogeneity. The barcode is based on the 13 marker Raman bands that include 478, 865, 940, 1049 and $1127 \mathrm{~cm}^{-1}$ for starch, 1003, 1586 and $1610 \mathrm{~cm}^{-1}$ for protein, 972, 1265, 1441, 1658 and $2851 \mathrm{~cm}^{-1}$ for TAG. Moreover, $I_{1658} / I_{1441}$ was included to indicate lipid unsaturation degree (Table 1).

As proof of concept, the barcode was employed to unveil the dynamics of main energy-storage compounds and their among-cell heterogeneity in C. reinhardtii CC124 and an oleaginous industrial microalga $N$. oceanica (strain IMET1; Additional file 1: Figure S1b), both under the stress of nitrogen deprivation. Panel I defines the averaged population-level features (Fig. 5a). For example, for $C$. reinhardtii $\mathrm{CC} 124$ cells during nitrogen deprivation, the marker Raman bands for both starch and TAG exhibited an upward tendency in intensity, while those for protein exhibited an opposite trend, which were consistent with the population-level measurements. On the other hand, the SCRS barcode of $N$. oceanica IMET1 revealed that a large amount of TAG, yet little starch, was accumulated under nitrogen deprivation, which was consistent with previous reports [7, 23]. Furthermore, comparison of the $I_{1658} / I_{1441}$ section of SCRS barcode suggested that the lipids $C$. reinhardtii and $N$. oceanica produced under nitrogen deprivation differed in property: increase in relative abundance of unsaturated lipids in the former (as indicated by the gradual increase of $I_{1658} / I_{1441}$ ratio), yet rapid decrease (particularly during the first day) of unsaturated lipids in the latter (Fig. 5a). Such a temporal shift in the unsaturation degree of lipids synthesized upon the onset of nitrogen deprivation is supported by our published time series lipidomics data for N. oceanica IMET1 [30].

Panel II of the barcode defines the corresponding HI for each of the quantitative traits in Panel I (Fig. 5b). For example, for $C$. reinhardtii $\mathrm{CC} 124$ cells under nitrogen deprivation, $\mathrm{HI}$ of most starch-related Raman bands exhibited a slight upward tendency at the early phase and gradually decreased afterward, which was largely consistent with the findings derived from the full spectrum of SCRS (Fig. 3d). For HI of TAG-related Raman bands, an upward trend was observed at the early phase, which was followed by a downward trend after around 4 days. This suggested that for TAG content, the among-cell heterogeneity increased first and then decreased. As for $N$. oceanica IMET1 under nitrogen deprivation, HI of protein-related Raman bands showed an upward tendency, yet on the opposite that of TAG-related Raman bands (as well as $\left.I_{1658} / I_{1441}\right)$ exhibited a downward tendency, suggesting decrease in among-cell heterogeneity in TAG content and lipid unsaturation degree during the process. Thus by graphically highlighting the temporal changes of metabolite contents and their heterogeneity, comparison of the SCRS barcodes unveiled the shared and distinct biosynthetic features between microalgal species. 

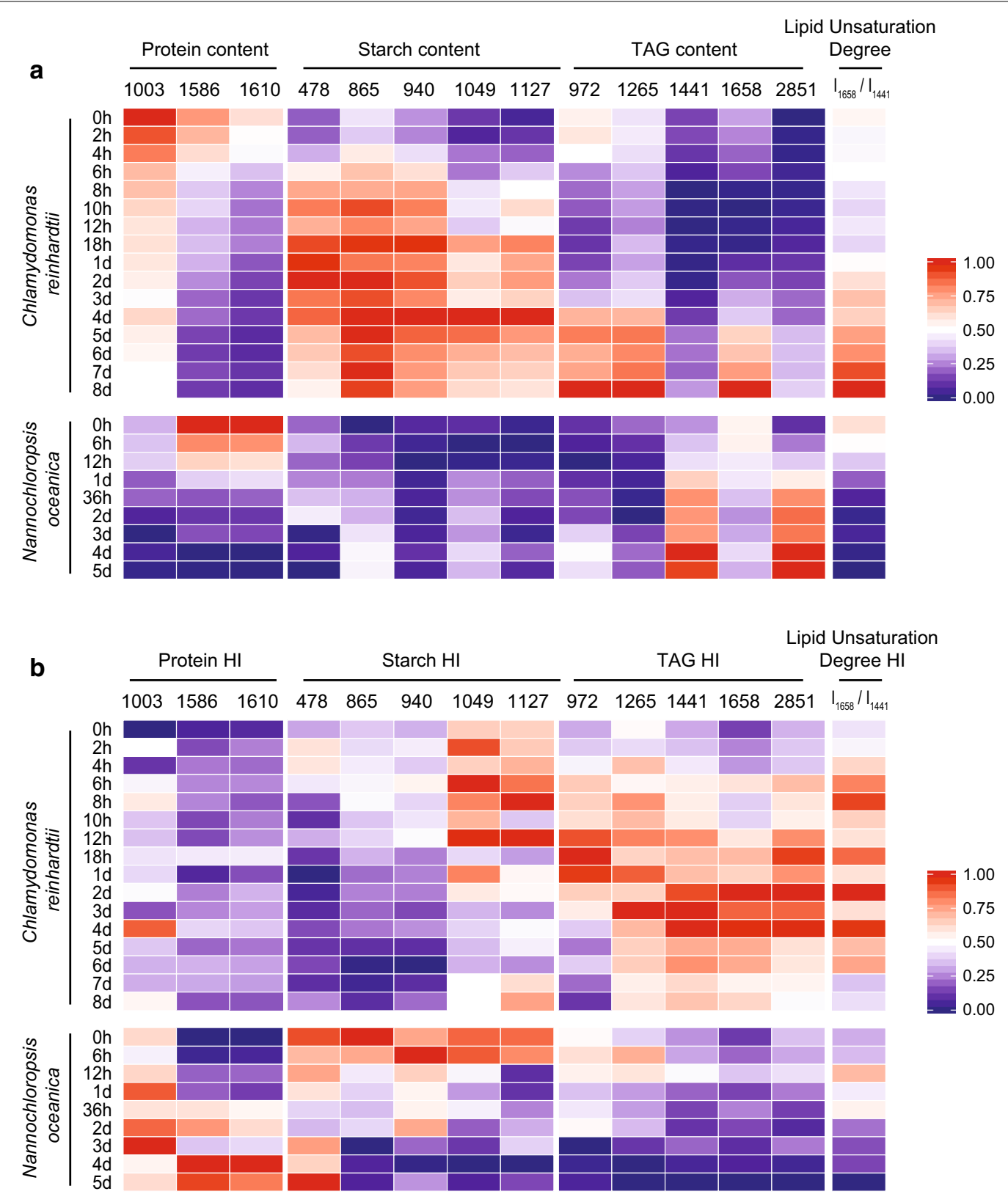

Fig. 5 SCRS barcodes of Chlamydomonas reinhardtii CC124 and Nannochloropsis oceanica IMET1 under nitrogen depletion conditions. Population average (a) and heterogeneity index (b) of protein content, starch content, TAG content and lipid unsaturation degree $\left(I_{1658} / I_{1441}\right)$ based on the 13 marker Raman bands in averaged SCRS of three biological replicates of culture at each time point are shown, which revealed graphically the distinct dynamic features of these key traits between the starch biosynthetic process of C. reinhardtii and the TAG-accumulating process of $N$. oceanica under nitrogen depletion conditions. The color of barcode indicates the relative intensity of Raman bands and was assigned based on the normalized intensity value within each Raman band

\section{Applicability of the method under a wide range of cell-storage conditions}

In many circumstance, fresh living cells may be unavailable prior to SCRS acquisition. In fact, freeze drying (i.e., lyophilization), which works by freezing the biomass and then reducing the surrounding pressure to allow the frozen water to sublime directly from the solid phase to the gas phase, is the most common storage condition for algal cells. To test whether the method is robust under common cell-storage conditions beyond suspension culture, wet $C$. 
(See figure on next page.)

Fig. 6 Quantification of starch, protein and TAG contents via single-cell Raman spectra from wet algal paste and dry algal powder. a Integrity of individual algal cells under the three algal cell-storage conditions of liquid suspension culture, wet algal paste and dry algal powder (Bar $=2 \mu \mathrm{m}$ ). The PLSR models for quantifying starch, protein and TAG contents via SCRS were built for cells in the form of wet algal paste (b) or dry algal powder (c). d Measurements of starch, protein and TAG contents for each of the three algal cell-storage conditions were highly consistent between the conventional method and the SCRS-based approach. PLSR: partial least square regression. TLC-GC-MS: thin-layer chromatography coupled with gas chromatography-mass spectrometry. $R^{2}$ : correlation coefficient. Larger error bar in TAG measurement might be caused by the relative low level of TAG content in C. reinhardtii cells and the multiple largely manual operations (e.g., lipid extraction and thin-layer chromatography) in determining the TAG content of the cellular biomass

reinhardtii cell pastes preserved in a $-80{ }^{\circ} \mathrm{C}$ refrigerator and dry C. reinhardtii powders lyophilized by vacuum freezing dryer were, respectively, analyzed by the SCRS approach. The results from simultaneous quantification of starch, protein, TAG contents and lipid unsaturation degree were compared to those from suspension culture.

Briefly, a small amount of wet algal paste or dry algal powder was first suspended in $\mathrm{ddH}_{2} \mathrm{O}$ and then intact cells under the microscope were subject to acquisition of SCRS (Fig. 6a). The PLSR models to quantify starch, protein and TAG by Raman spectra of wet algal paste or dry algal powder were established and validated similarly to that of live cells in liquid suspension culture. For wet algal paste, SCRS-based quantification of starch, protein and TAG contents was accurate and reliable, as demonstrated by the high coefficient values $\left(R^{2}\right)$ for both calibration datasets and validation datasets (the overall $R^{2}$ reached 0.9855, 0.9864 and 0.9318; Fig. 6b; Additional file 10: Table S1). The performance was similar for dry algal powders, since the overall $R^{2}$ reached $0.9827,0.9923$ and 0.9568 respectively (Fig. 6c; Additional file 10: Table S1). Importantly, no significant difference was found in starch, protein and TAG contents among those measured by conventional methods and those predicted via SCRS in liquid suspension culture, wet paste or dry powder (Student $t$ test, $P>0.1$; Fig. 6d).

As for lipid unsaturation degree, the $I_{1658} / I_{1441}$ derived from SCRS as measured via both wet algal paste and dry algal power showed significant positive correlation with that measured by GC-MS $\left(R^{2}=0.6342\right.$ and 0.6233 respectively). Thus, SCRS acquired from wet algal paste and dry algal power can also be interpreted for lipid unsaturation degree of individual cells. Therefore, the SCRS approach appears to be generally applicable to a wide range of cell-storage conditions, including those most commonly used in preservation and storage of biological samples (e.g., cryopreservation or lyophilization).

\section{Conclusion and discussion}

"Ramanome", i.e., a collection of SCRS randomly sampled from a cellular population at a given condition and time, captures the "metabolomic state" of cells in a rapid, labelfree, non-invasive and single-cell resolution manner [18].
Here, we demonstrated that the SCRS of C. reinhardtii is able to simultaneously quantify four key phenotypes of microalgae-based production: starch content, protein content, TAG content and lipid unsaturation degree. The marker peaks that can model the quantity of these major intracellular energy-storage compounds were identified and their performance was critically assessed (Table 1). Quantitative models based on the full spectrum of SCRS provide higher accuracy than those based on the marker peaks; thus, such models can be established and then shared as a valuable community resource for SCRS-based analysis and screening of microbial cell factories and biological processes mediated by them.

Phenotypic heterogeneity among cells, a universal trait of cellular populations, can dramatically affect cellular processes and thus lead to profound biological implications or practical applications. For example, substantial cell-to-cell variations might be advantageous to the robustness of the cellular population and subject to evolutionary selection [31, 32]. In contrast, for many industrial biotechnological processes, a high degree of heterogeneity can cause low yields, suboptimal productivity or even failures [33,34]. In this study, the degree of heterogeneity of energy-storage compounds (i.e., starch and TAG) decreased sharply at the early phase and stabilized at low level later under the stress of nitrogen deprivation. The observation reflects the dynamic response and eventual homeostasis of $C$. reinhardtii cells under stress and might serve as a direct indicator for bioprocess monitoring and control. Therefore, the ability to track the heterogeneity of multiple physiological parameters (i.e., starch content, protein content, TAG content and lipid unsaturation degree) in a rapid, labelfree and simultaneous manner should be of value to the dissection of mechanisms underlying cellular systems' performance, and to the optimization and control of bioprocesses.

Actually, single-cell Raman spectra can potentially capture two levels of heterogeneity for an isogenic cellular population: intracellular heterogeneity and intercellular heterogeneity. On one hand, when the diameter of the laser spot is smaller than the cell size, one SCRS theoretically samples only a particular region of a cell. This leads 


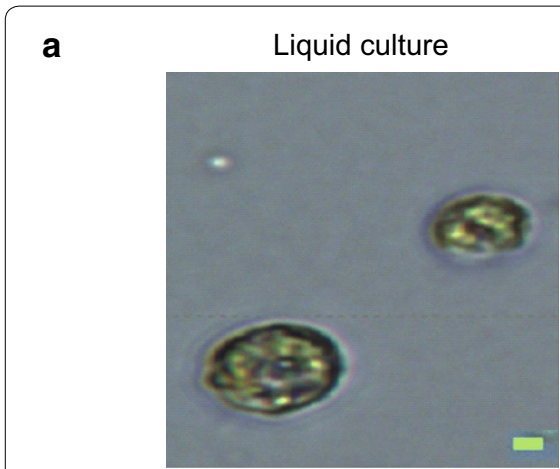

b
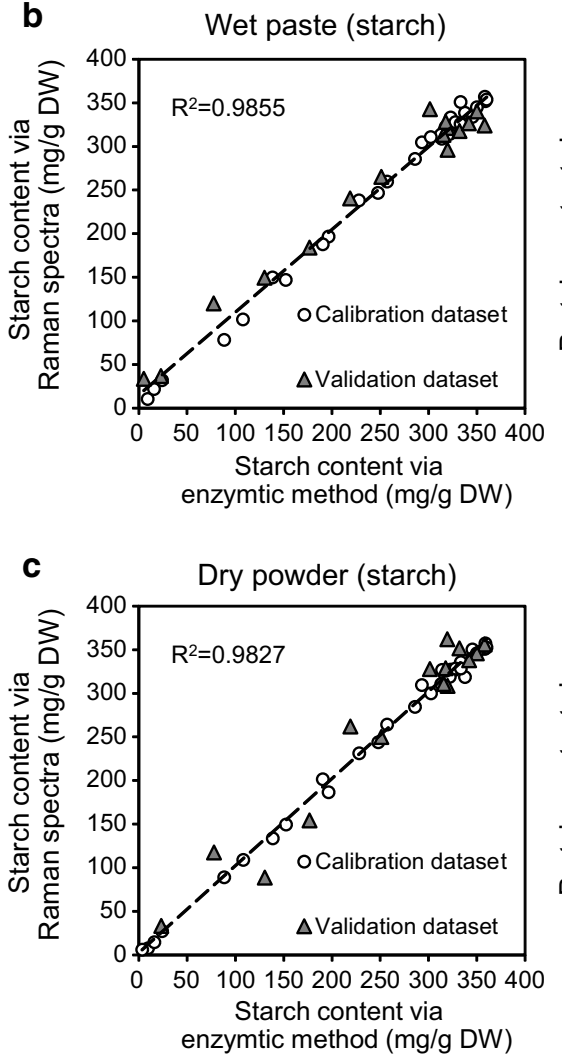

d

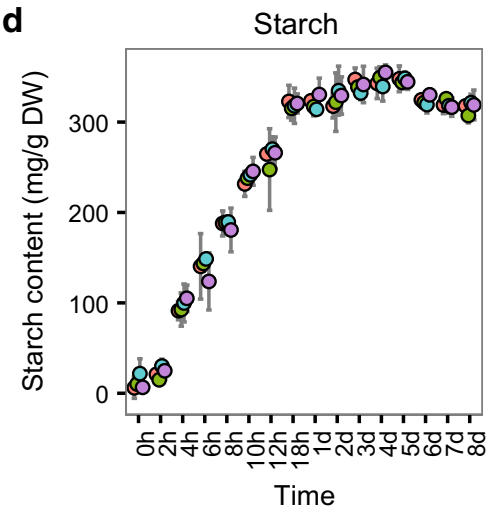

Wet paste

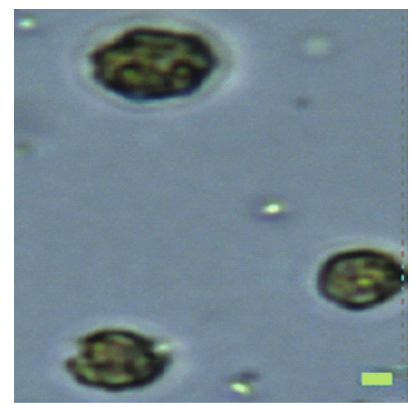

Wet paste (protein)

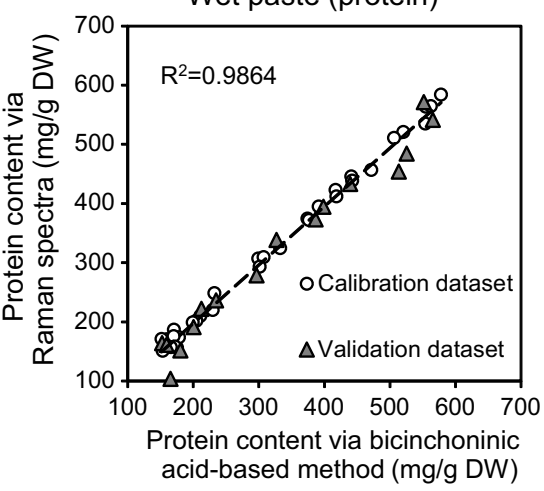

Dry powder (protein)
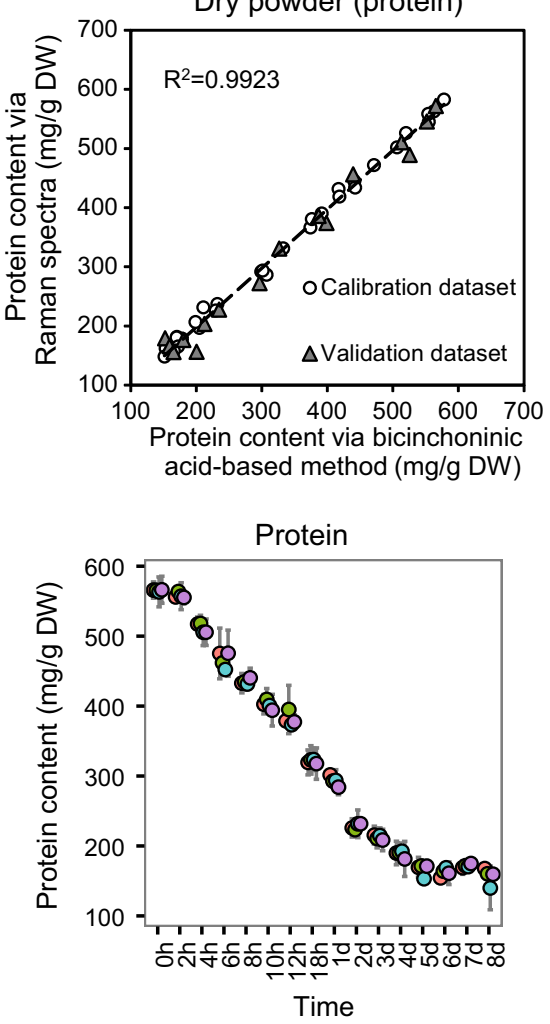

Dry powder

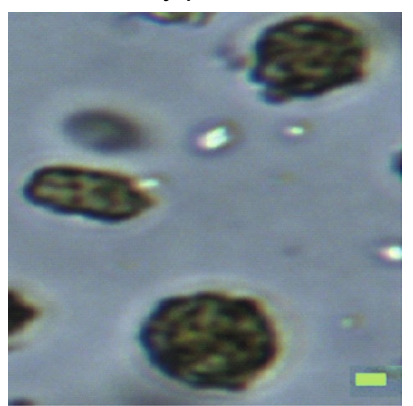

Wet paste (TAG)
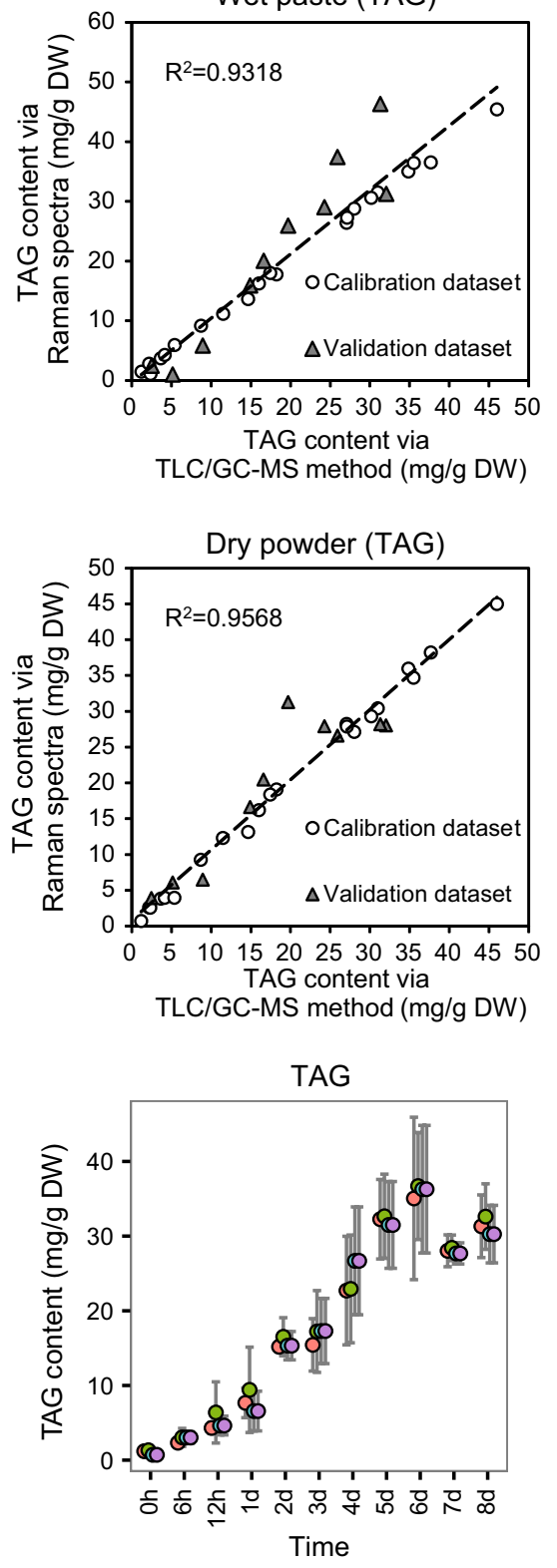

o Convenional methods

o Liquid culture

o Wet paste

o Dry powder 
to SCRS variation among regions in a cell, i.e., the intracellular heterogeneity. On the other hand, at any given state of an isogenic population, phenotypes among cells can vary greatly, due to difference in cell cycle phases, micro-environmental conditions and even spontaneous mutations [33]. This leads to intercellular heterogeneity.

To assess the intracellular heterogeneity, a recent study compared three Raman spectra acquisition modes, i.e., single spectra, spectra of images and integrated Raman spectra, for the classification of large eukaryotic cells (i.e., $\mathrm{T}$ lymphocyte and pancreatic cell lines). To overcome the effects of intracellular heterogeneity, acquisition of integrated Raman spectra that covered an $8 \times 8 \mu^{2}$ region of a cell was suggested for classification of cells [35]. A related study estimated a minimum number of local spectra sampling within a cell (i.e., "sampling density" instead of "sampling depth") for characterizing single cells of lymphocytes ( $20 \mu \mathrm{m}$ of cell diameter), and claimed that 30 measurements of Raman spectra from random locations within a cell showed a performance that is similar to that of acquiring a whole-cell Raman image [36]. Both of these studies stressed that intracellular heterogeneity affected the ability of Raman spectra to characterize or classify cells and proposed ways to overcome these intracellular heterogeneities. However, they did not address intercellular heterogeneity within a cellular population. In contrast, our manuscript mainly addressed intercellular heterogeneity, i.e., the effect of sample size (i.e., "sampling depth") per cellular population on the performance of SCRS in characterizing cells, using microalgal cells (of $\sim 10 \mu \mathrm{m}$ in diameter and thus are much smaller than lymphocytes) as a model.

Due to the presence of intracellular heterogeneity, large cells typically require acquisition of multiple SCRS to properly characterize them (e.g., the lymphocyte cells mentioned above). However, for small size cells, the overall functional state can be described by a single SCRS, especially measured under aqueous conditions. In this study, SCRS of $C$. reinhardtii cells were acquired via Raman tweezers which used the $532 \mathrm{~nm}$ laser and $50 \times$ objective to create an optical trap for holding individual cells under aqueous condition, and the same laser was used to acquire the whole-cell spectra. Importantly, when the cell was held in the single-beam gradient force trap, the cell under the aqueous condition was rolling in random orientation. Therefore, our measurements represent the averaged spectra of a whole cell instead of a specific region in the cell.

The presence and importance of intercellular heterogeneity, both for diversity of SCRS as a whole and for a particular SCRS-derived phenotype, demands methods to quantitatively determine minimal sampling depth. Here, we showed that sampling depth, a parameter generally ignored in past studies, greatly influences the accuracy and reliability of SCRS-based measurement. Moreover, we proposed two kinds of "minimal sampling depth" for a given population "state": (i) for exploring diversity of SCRS, the minimal sampling depth is defined as the depth when no more than $1 \%$ of increasement in cumulative DI is gained by sampling one more cell; (ii) for measuring the mean and $\mathrm{HI}$ of a particular phenotype such as metabolite content, minimal sampling depth is defined based on the boundary condition of deviation of no more than $5 \%$ from the true means or true HI. The methodology introduced here to rationally determine minimal sampling depth for a given population is generally applicable. It should not only guide the design of future studies, but also enable retrospective assessment of past studies that either sampled at only a few cells per population [24-26] or offered no rationale for their choice of sampling depth for a particular system [19, 22, 23, 27, 28]. Our study also suggests that efforts to automate SCRS acquisition from a given sample will be highly valuable, as it might allow routine analysis at sampling depth of dozens or even hundreds of cells.

Due to the rich information harbored in the SCRS, the type and number of phenotypes that can be tackled by SCRS are theoretically unlimited. For example, as many valuable compounds carry characteristic Raman signal, this method should be able to rapidly provide a landscape-like view of biosynthetic capability of cells at single-cell resolution. Moreover, SCRS can be interpreted for a much greater range of phenotypes beyond metabolite profile: for example, SCRS has recently been used to characterize substrate metabolism [37, 38], metabolic activity [39], stress response [18, 40] and interspecies interactions $[37,41]$. Therefore to gauge and fulfill the potential of the SCRS approach, one research direction is to probe whether, and to what degree, the plethora of phenotypes can be simultaneously measured or modeled via SCRS. On the other hand, considering that acquisition of SCRS is non-destructive and cells of targeted SCRS can be subsequently isolated by Raman-activated cell sorting (RACS) [42-44], novel applications such as Raman-activated mutant screening, which links SCRS-based phenotyping to sequencing at single-cell resolution, might be possible and deserve investigation.

Finally, as it requires only a trace number of cells, yet its performance is insensitive to variation in sample storage conditions, SCRS approach might find particular value in circumstances where cells grow slowly (or are yet to be cultured), SCRS acquisition cannot be performed onsite, or only cryopreserved or lyophilized biomass is available. This good feature can be taken advantage of to greatly expand the application of SCRS and Raman-activated cell sorting and sequencing technologies [45]. 


\section{Methods}

\section{Strains and growth conditions}

Chlamydomonas reinhardtii strain $\mathrm{CC} 124$ was grown in standard Tris acetate phosphate (TAP) medium at $25^{\circ} \mathrm{C}$ under continuous lighting (approximate $150 \mu \mathrm{mol}$ photons $\mathrm{m}^{-2} \mathrm{~s}^{-1}$ ) and bubbled with air to ensure mixing and prevent settling. Cells grown to late log phase were reinoculated to a final concentration of $2 \times 10^{6}$ cells $\mathrm{mL}^{-1}$ in nitrogen-depleted TAP medium, in which $\mathrm{NH}_{4} \mathrm{Cl}$ was omitted. The re-inoculation was carried out in triplicate cultures. One milliliter of cell culture was collected at $0 \mathrm{~h}$ (right after inoculation), 2, 4, 6, 8, 10, 12, $18 \mathrm{~h}$ and 1, 2, 3, 4, 5, 6, 7 and 8 days for analysis. Nannochloropsis oceanica IMET1 were grown in a modified $\mathrm{f} / 2$ liquid medium with $4 \mathrm{mM} \mathrm{NO}_{3}{ }^{-}$under continuous light (approximately $50 \mu \mathrm{mol}$ photons $\mathrm{m}^{-2} \mathrm{~s}^{-1}$ ) at $25^{\circ} \mathrm{C}$ and induced in nitrogen depletion $\mathrm{f} / 2$ medium, in which $\mathrm{NO}_{3}{ }^{-}$was omitted. Cultures in triplicate at 0, 6, 12 h, 1 day, 36 h and 2, 3, 4 and 5 days were sampled.

\section{Quantification of starch, protein, TAG content and lipid unsaturation degree in cultures}

The algal biomass was lyophilized via vacuum freezing dryer. The starch content of the dry algal biomass was quantified using an enzymatic starch assay kit (Megazyme K-TSTA 07/11). Briefly, samples of about $20 \mathrm{mg}$ dry algal power were treated with $80 \%$ ethanol to remove sugars, hydrolyzed into soluble maltodextrins with thermostable $\alpha$-amylase and then digested into D-glucose with amyloglucosidase. The generated glucose was exposed to a reagent containing glucose oxidase, peroxidase and 4-aminoantipyrine and then its content quantified spectrophotometrically at a wavelength of $510 \mathrm{~nm}$.

The total protein content of algal cultures was measured as previously reported [7]. Briefly, approximately $10 \mathrm{mg}$ of lyophilized algal biomass was hydrolyzed in $200 \mu \mathrm{L}$ lysis buffer ( $1 \mathrm{M}$ sodium hydroxide, $\mathrm{NaOH}$ ) and then incubated at $80{ }^{\circ} \mathrm{C}$ for $10 \mathrm{~min}$ in a water bath. Then, $800 \mu \mathrm{L}$ $\mathrm{ddH}_{2} \mathrm{O}$ was added to the hydrolysate to bring the volume to $1 \mathrm{~mL}$. Cellular debris was centrifuged at $12,000 \mathrm{~g}$ for 30 min before the supernatant was transferred to a new tube. The extraction was repeated two more times and all the supernatant extracts were pooled together. Then, the total protein in the supernatant was determined by the BCA Protein Assay kit (cat no. cw0014s).

Thin-layer chromatography coupled with gas chromatography-mass spectrometry (TLC-GC-MS) and gas chromatography-mass spectrometry (GC-MS) was performed to analyze the TAG content and the lipid unsaturation degree of the total lipids. The procedures mainly included total lipid extraction, TLC, transesterification and GC-MS analysis [7]. Specifically, total lipids of about $30 \mathrm{mg}$ lyophilized algal powder were extracted with $6 \mathrm{~mL}$ chloroform:methanol $(2: 1, \mathrm{v} / \mathrm{v})$ and recovered in chloroform:methanol $(2: 1, \mathrm{v} / \mathrm{v})$. For TAG quantification, around $0.3 \mathrm{mg}$ lipid extract was loaded onto $10 \times 20 \mathrm{~cm}$ silica TLC plates (Merck KGaA, Darmstadt, Germany). TAG was separated, visualized and scraped from the plate. Then TAG was extracted with chloroform:methanol (2:1, v/v) from TLC powder and used to prepare fatty acid methyl esters (FAMEs) as previously described [7]. Briefly, $20 \mu \mathrm{L} 2 \mathrm{mg} \mathrm{mL}^{-1}$ methyl tridecanoate (C13Me), $200 \mu \mathrm{L}$ chloroform:methanol (2:1, $\mathrm{v} / \mathrm{v})$ and $300 \mu \mathrm{L} 5 \%(\mathrm{v} / \mathrm{v}) \mathrm{HCl}$ :methanol were added to TAG extracts, which were transesterified in tightly sealed vials at $85{ }^{\circ} \mathrm{C}$ for $1 \mathrm{~h}$. Finally, the FAMEs extracted were analyzed on an Agilent 7890-5975C gas chromatography mass spectrometer fitted with an HP-INNOWAX $30 \mathrm{~m} \times 0.25 \mathrm{~mm} \times 0.25 \mu \mathrm{m}$ column. The FAMEs were quantified using pentadecane as the internal standard and C8-C24 FAMEs mixture as FAMEs standards. The TAG content was determined by conversion from the content of FAMEs.

To measure the lipid unsaturation degree of total lipids from bulk microalgal biomass, $1 \mathrm{mg}$ total lipid extract was directly transesterified to FAMEs, which were then analyzed via GC-MS as described above. The abundance of individual fatty acids in the total lipid extract was calculated based on the GC-MS data. The lipid unsaturation degree was calculated via the ratio between the number of $\mathrm{C}=\mathrm{C}$ bonds and the number of $\mathrm{CH}_{2}$ bonds of total fatty acids as previously described [23, 27, 29]. Briefly, the average mass unsaturation ration $N_{\mathrm{C}=\mathrm{C}} / N_{\mathrm{CH} 2}$ can be represented as $\sum\left(\mathrm{niN}_{\mathrm{C}=\mathrm{C}}^{i}\right) / \sum\left(\mathrm{niN}_{\mathrm{CH} 2}^{i}\right)$, where ni refers to the relative abundance of the individual fatty acids in the total lipid extract (mg/mg dry weight), $N_{\mathrm{C}=C}^{i}$ refers to the number of $\mathrm{C}=\mathrm{C}$ bonds of the individual fatty acids and $N_{\mathrm{C}=\mathrm{C}}^{i}$ refers to the number of $\mathrm{CH}_{2}$ bonds.

\section{Fluorescent microscopy and transmission electron microscopy}

For microalgal cells sampled at $0,12 \mathrm{~h}$ and 1, 3, 5 and 7 days, lipid droplets were first stained by Nile Red (Sigma, USA). Briefly, $5 \mu \mathrm{L}$ of stock Nile Red solution $(50 \mu \mathrm{g} / \mathrm{mL})$ was added to $0.5 \mathrm{~mL}$ microalgae culture and incubated in the dark for $10 \mathrm{~min}$. Fluorescence images were then acquired using an Olympus BX51 florescence microscope with a $100 \times / 1.3$ oil immersion objective and U-MWB2 mirror unit. For transmission electron microscopy, microalgae cells were sampled at $0 \mathrm{~h}$ and 3 and 5 days and then centrifuged ( $500 g, 5 \mathrm{~min})$. Cell pellets were fixed by $2.5 \%$ glutaraldehyde for $12 \mathrm{~h}$ at $4{ }^{\circ} \mathrm{C}$ and then washed three times with phosphate-buffered saline (PBS, pH7.4). After post-fixation in 1\% osmic acid for $1 \mathrm{~h}$, samples were again washed three times with PBS. The samples were dehydrated through an acetone series 
(30-95\%; followed by pure acetone three times) and then embedded in Spurr's resin. Micrographs of ultrathin sections were captured using a Hitachi H-7650 transmission electron microscope (Hitachi High-Technologies Co., Japan).

\section{Acquisition of single-cell Raman spectra}

Single-cell Raman spectra were measured using a modified Horiba LabRam HR with an excitation wavelength of $532 \mathrm{~nm}$ [44]. For acquisition of SCRS from live cells, $1 \mathrm{~mL}$ of microalgal culture was collected at each of the time points. After centrifugation, cells were washed with $\mathrm{ddH}_{2} \mathrm{O}$ for three times and loaded into a capillary tube (50 mm length $\times 1 \mathrm{~mm}$ width $\times 0.1 \mathrm{~mm}$ height, Camlab, UK). The Raman spectra of 20 cells and four background sites in each of the three biological replicate cultures (i.e., 60 cells per time point) were randomly recorded. Briefly, an individual cell was trapped, photobleached and measured by a $532 \mathrm{~nm}$ laser with about $25 \mathrm{~mW}$ output power. Each Raman spectrum was acquired between 393.8 and $3341.3 \mathrm{~cm}^{-1}$ and the acquisition time was $2 \mathrm{~s}$.

For preparation of wet algal pastes, $10 \mathrm{~mL}$ of each algal culture was centrifuged at $3000 \mathrm{~g}$ and cell pellets preserved at $-80{ }^{\circ} \mathrm{C}$ until use. For preparation of dry algal powders, the wet algal pastes were lyophilized in a vacuum freezing dryer for $24 \mathrm{~h}$ and then stored at $-80{ }^{\circ} \mathrm{C}$ until use. Before SCRS acquisition, aliquots of the wet algal paste thawed at $4{ }^{\circ} \mathrm{C}$ or about $1 \mathrm{mg}$ of dry algal powders were resuspended in $0.2 \mathrm{~mL} \mathrm{dd}_{2} \mathrm{O}$ by gentle shaking, and then SCRS of individual algal cells were acquired as described above.

\section{Analysis of single-cell Raman spectra}

Raw SCRS were pre-processed for background subtraction, baseline correction and normalization with Labspec5 software (HORIBA JobinYvon Ltd., UK). Two information-rich regions of SCRS, the biochemical fingerprint region $\left(393.8-1801.4 \mathrm{~cm}^{-1}\right)$ and the hydrocarbon region $\left(2701.6-3051.6 \mathrm{~cm}^{-1}\right)$, were separately extracted for further analysis [46]. For both regions, a spectrum was normalized via division by its area. PLSR, a method for developing multivariate calibration models to study correlation between the investigated properties and spectroscopic data, was employed to predict the starch, protein and TAG contents from SCRS at both the population level and the single-cell level as previously described $[23,47]$. At certain time points, the predicted starch, protein or TAG contents of a small number of cells were lower than the detection threshold (i.e., $<0 \mathrm{mg} / \mathrm{g} \mathrm{DW}$ ); these contents were regarded as $0 \mathrm{mg} / \mathrm{g}$ DW in subsequent analysis. the ratio of the intensity of the two Raman bands at $1658 \mathrm{~cm}^{-1}$ (cis $\mathrm{C}=\mathrm{C}$ stretching mode which is proportionate to the amount of unsaturated $\mathrm{C}=\mathrm{C}$ bonds) and $1441 \mathrm{~cm}^{-1}\left(\mathrm{CH}_{2}\right.$ scissoring mode which is proportionate to the amount of saturated $\mathrm{C}-\mathrm{C}$ bonds) was employed to estimate the lipid unsaturation degree [23, 27, 29]. Procedures to quantify the starch, protein and TAG content via SCRS of wet algal paste and dry algal powder were established and validated in a manner similar to that of live microalgal cells in liquid suspension culture. PLSR models were produced using Matlab R2010a (Mathworks, USA).

\section{Quantifying the influence of sampling depth on measurement accuracy}

The degree of divergence between the two SCRS was quantified via the Euclidian distance between any pair of SCRS sampled from a given population. Diversity index (DI), i.e., the maximal Euclidian distance among the set of SCRS sampled in an SCRS population, was proposed to quantify the observed diversity of SCRS for a particular state of a given cell population. Cumulative diversity index was proposed to estimate the observed SCRS diversity in a series of SCRS collections sampled at a particular depth for a particular state of the population. To perform saturation analysis, whether for a time point (60 cells) or for the collective cells from all the 16 time points (960 cells), an SCRS collection was acquired by randomly sampling the population for SCRS at a particular sampling depth that ranged from two to all cells, and such trials were performed for 1000 times at each sampling depth. At each sampling depth, the mean and standard deviation of the cumulative DI were calculated to estimate the extent to which the diversity of SCRS was observed and the variation of the observation. The mean and standard deviations were then, respectively, plotted against the sampling depth, so as to quantitatively model their interaction. To quantitatively determine whether the cumulative DI (cumDI) of an SCRS pool at each time point was saturated at a certain sampling depth, we defined the "rate of cumDI":

$$
\text { Rate of cumDI }(N)=\frac{\operatorname{cumDI}_{N}-\operatorname{cumDI}_{N-1}}{\operatorname{cumDI}_{N-1}},
$$

where $N$ : sample depth; cumDI $\mathrm{I}_{\mathrm{N}}$ : cumDI at the sampling depth of $N$ cells for a population; $\operatorname{cumDI}_{N-1}$ : cumDI at the sampling depth of $(N-1)$ cells for a population. For each of the time points, the relationship between the rate of cumDI and sampling depth was thus plotted. We set a cutoff of $1 \%$ for the rate of cumDI to define the "minimal sampling depth", which means, at this particular sampling depth, no more than $1 \%$ of gain in cumDI will be gained by sampling one more cell.

To assess the influence of sampling depth on the measurement of traits and their respective among-cell heterogeneity, cumulative mean (cumMean) was proposed as the average of the quantitative traits (e.g., contents 
of starch, protein or TAG) modeled via SCRS based on a number of individual cells, and cumulative heterogeneity index (cumHI) as the degree of heterogeneity for each of the quantitative traits among the cells sampled, in a series of SCRS collections sampled at a particular depth for a particular state of the population. To perform saturation analysis at each time point, an SCRS collection was acquired (and mean and $\mathrm{HI}$ of the quantitative traits calculated) by randomly sampling the population for SCRS at a particular sampling depth that ranged from one to all cells, and such trials were performed 1000 times at each sampling depth. At each sampling depth, the cumMean and cumHI were calculated to estimate the observed values of quantitative traits and the variation of such observations. The cumMean and cumHI were then, respectively, plotted against the sampling depth, so as to quantitatively assess how the choice of sampling depth affects the accuracy and reliability of measuring the traits. To quantitatively assess the effect of sampling depth on the cumMean and cumHI, the relationship between standard deviation (from 1000 trials) and the sampling depth per population was plotted for each time point. The minimal sampling depth for computing mean contents and mean HI (of starch, protein or TAG) was determined based on a threshold of $5 \%$ in the standard deviation of the 1000 permutations, which corresponds to a deviation of no more than $5 \%$ from the true means of metabolite contents or their $\mathrm{HI}$ in each measurement.

\section{Additional files}

Additional file 1: Figure S1. Growth curves of Chlamdomonas reinhardtii CC124 and Nannochloropsis oceanica IMET1 under the condition of nitrogen depletion (N-). The microalgal growth was tracked via $\mathrm{OD}_{750}$.

Additional file 2: Figure S2. Detection of neutral lipid accumulation in Chlamdomonas reinhardtii cells by Nile Red staining.

Additional file 3: Figure S3. Transmission electron microscopy images tracking the accumulation of lipid bodies and starch granules in Chlamdomonas reinhardtii cells under the condition of nitrogen depletion.

Additional file 4: Figure S4. Temporal dynamics of lipid unsaturation degree at the population level and the single-cell level.

Additional file 5: Dataset S1. Dataset for building and validating the PLSR model for starch content quantification in Chlamydomonas reinhardtii CC124 cells.

Additional file 6: Dataset S2. Dataset for building and validating the PLSR model for protein content quantification in Chlamydomonas reinhardtii CC124 cells.

Additional file 7: Dataset S3. Dataset for building and validating the PLSR model for TAG content quantification in Chlamydomonas reinhardtii CC124 cells.

Additional file 8: Appendix S1. Matlab script for building and validating the PLSR models for quantification of starch, protein and TAG contents.

Additional file 9: Figure S5. Computation of "Minimal Sampling Depth".

Additional file 10: Table S1. Performance of PLSR models for starch, protein and TAG quantification under the cell-storage conditions of liquidsuspension culture, wet paste and dry powder.

\section{Abbreviations}

cumHI: cumulative heterogeneity index; cumMean: cumulative mean; DW: dry weight; DI: diversity index; FAMEs: fatty acid methyl esters; GC-MS: gas chromatography-mass spectrometry; HI: heterogeneity index; MS: mass spectrometry; PLSR: partial least square regression; $R^{2}$ : coefficient value; $R S D$ : relative standard deviation; SCRS: single-cell Raman spectra; TAG: triacylglycerol; TAP: tris acetate phosphate; TLC-GC-MS: thin-layer chromatography coupled with gas chromatography-mass spectrometry.

\section{Authors' contributions}

$J X, Y H$ and $P Z$ designed the research. $Y H$ and $P Z$ performed experiments. $Y H$, SH, PZ and JX analyzed the data. YJ and TW provided critical suggestions. JX, $\mathrm{YH}$, and $\mathrm{SH}$ wrote the manuscript. All authors read and approved the final manuscript.

\section{Author details}

${ }^{1}$ Single-Cell Center, CAS Key Laboratory of Biofuels and Shandong Key Laboratory of Energy Genetics, Qingdao Institute of BioEnergy and Bioprocess Technology, Chinese Academy of Sciences, Qingdao, Shandong, China. ${ }^{2}$ University of Chinese Academy of Sciences, Beijing, China. ${ }^{3}$ Laboratory for Marine Biology and Biotechnology, Qingdao National Laboratory for Marine Science and Technology, Qingdao, Shandong, China.

\section{Acknowledgements}

J.X. acknowledges support of Grants 31327001 and 31425002 from NSFC and XDB15040100 from CAS. S.H. acknowledges support from NSFC (31400089) and China Postdoctoral Science Foundation Grant (2016LH00036). Y.J. acknowledges support of ZR2014CQ005, 2015ZDJS04002 from Shandong Province. Y.J. is grateful to the partial support from the State Development \& Investment Corporation (SDIC).

\section{Competing interests}

The authors declare that they have no competing interests.

\section{Ethics approval and consent to participate}

Not applicable.

\section{Publisher's Note}

Springer Nature remains neutral with regard to jurisdictional claims in published maps and institutional affiliations.

Received: 3 August 2017 Accepted: 10 November 2017

Published online: 17 November 2017

References

1. Wijffels RH, Barbosa MJ. An outlook on microalgal biofuels. Science. 2010;329:796-9.

2. Mussatto SI, Dragone G, Guimarães PM, Silva JP, Carneiro LM, Roberto IC, Vicente A, Domingues L, Teixeira JA. Technological trends, global market, and challenges of bio-ethanol production. Biotechnol Adv. 2010;28:817-30.

3. Hu Q, Sommerfeld M, Jarvis E, Ghirardi M, Posewitz M, Seibert M, Darzins A. Microalgal triacylglycerols as feedstocks for biofuel production: perspectives and advances. Plant J. 2008;54:621-39.

4. Smith AM, Zeeman SC. Quantification of starch in plant tissues. Nat Protoc. 2006;1:1342-5.

5. Rose R, Rose CL, Omi SK, Forry KR, Durall DM, Bigg WL. Starch determination by perchloric acid vs enzymes: evaluating the accuracy and precision of six colorimetric methods. J Agr Food Chem. 1991;39:2-11.

6. Berges JA, Fisher AE, Harrison PJ. A comparison of Lowry, Bradford and Smith protein assays using different protein standards and protein isolated from the marine diatom Thalassiosira pseudonana. Mar Biol. 1993;115:187-93.

7. Jia J, Han D, Gerken HG, Li Y, Sommerfeld M, Hu Q, Xu J. Molecular mechanisms for photosynthetic carbon partitioning into storage neutral lipids in Nannochloropsis oceanica under nitrogen-depletion conditions. Algal Res. 2015;7:66-77. 
8. Oikawa A, Saito K. Metabolite analyses of single cells. Plant J. 2012:70:30-8.

9. Zenobi R. Single-cell metabolomics: analytical and biological perspectives. Science. 2013;342:1243259.

10. Ibáñez AJ, Fagerer SR, Schmidt AM, Urban PL, Jefimovs K, Geiger P. Dechant R, Heinemann M, Zenobi R. Mass spectrometry-based metabolomics of single yeast cells. Proc Natl Acad Sci USA. 2013;110:8790-4.

11. Deuschle K, Fehr M, Hilpert M, Lager I, Lalonde S, Looger LL, Okumoto S, Persson J, Schmidt A, Frommer WB. Genetically encoded sensors for metabolites. Cytom Part A. 2005;64A:3-9.

12. Okumoto S. Imaging approach for monitoring cellular metabolites and ions using genetically encoded biosensors. Curr Opin Biotech. 2010:21:45-54.

13. Nielsen $\sqcup$, Olsen LF, Ozalp VC. Aptamers embedded in polyacrylamide nanoparticles: a tool for in vivo metabolite sensing. ACS Nano. 2010;4:4361-70.

14. Win MN, Smolke CD. A modular and extensible RNA-based gene-regulatory platform for engineering cellular function. Proc Natl Acad Sci USA. 2007;104:14283-8.

15. Huang WE, Griffiths RI, Thompson IP, Bailey MJ, Whiteley AS. Raman microscopic analysis of single microbial cells. Anal Chem. 2004;76:4452-8.

16. Butler HJ, Ashton L, Bird B, Cinque G, Curtis K, Dorney J, Esmonde-White K, Fullwood NJ, Gardner B, Martin-Hirsch PL. Using Raman spectroscopy to characterize biological materials. Nat Protoc. 2016;11:664-87.

17. Lorenz B, Wichmann C, Stöckel S, Rösch P, Popp J. Cultivation-free Raman spectroscopic investigations of bacteria. Trends Microbiol. 2017;25:413-24

18. Teng L, Wang $X$, Wang $X$, Gou H, Ren L, Wang T, Wang $Y$, Ji Y, Huang WE, Xu J. Label-free, rapid and quantitative phenotyping of stress response in $E$. coli via ramanome. Sci Rep. 2016;6:34359-68.

19. Wakisaka Y, Suzuki Y, Iwata O, Nakashima A, Ito T, Hirose M, Domon R, Mai S, Tsumura N, Watarai H. Probing the metabolic heterogeneity of live Euglena gracilis with stimulated Raman scattering microscopy. Nat Microbiol. 2016;1:16124.

20. Li K, Cheng J, Ye Q, He Y, Zhou J, Cen K. In vivo kinetics of lipids and astaxanthin evolution in Haematococcus pluvialis mutant under 15\% CO2 using Raman microspectroscopy. Bioresource Technol. 2017; In Press.

21. Moudríková Š, Mojzeš P, Zachleder V, Pfaff C, Behrendt D, Nedbal L. Raman and fluorescence microscopy sensing energy-transducing and energy-storing structures in microalgae. Algal Res. 2016;16:224-32.

22. Ji Y, He Y, Cui Y, Wang T, Wang Y, Li Y, Huang WE, Xu J. Raman spectroscopy provides a rapid, non-invasive method for quantitation of starch in live, unicellular microalgae. Biotechnol J. 2014;9:1512-8.

23. Wang T, Ji Y, Wang Y, Jia J, Li J, Huang S, Han D, Hu Q, Huang WE, Xu J. Quantitative dynamics of triacylglycerol accumulation in microalgae populations at single-cell resolution revealed by Raman microspectroscopy. Biotechnol Biofuels. 2014;7:58-70.

24. Chiu L, Ho S, Shimada R, Ren N, Ozawa T. Rapid in vivo lipid/carbohydrate quantification of single microalgal cell by Raman spectral imaging to reveal salinity-induced starch-to-lipid shift. Biotechnol Biofuels. 2017:10:9-18

25. Hosokawa M, Ando M, Mukai S, Osada K, Yoshino T, Hamaguchi HO, Tanaka T. In vivo live cell imaging for the quantitative monitoring of lipids by using Raman microspectroscopy. Anal Chem. 2014;86:8224-30.

26. Samek $\mathrm{O}$, Obruča S, Šiler M, Sedláček P, Benešová P, Kučera D, Márova I, Ježek J, Bernatová S, Zemánek P. Quantitative Raman spectroscopy analysis of polyhydroxyalkanoates produced by Cupriavidus necator $\mathrm{H} 16$. Sensors. 2016;16:1808-14.

27. Wu H, Volponi JV, Oliver AE, Parikh AN, Simmons BA, Seema S. In vivo lipidomics using single-cell Raman spectroscopy. Proc Natl Acad Sci USA. 2011;108:3809-14.

28. Chiu Y, Huang C, Shigeto S. In vivo probing of the temperature responses of intracellular biomolecules in yeast cells by label-free Raman microspectroscopy. ChemBioChem. 2013;14:1001-5.

29. Ota S, Alexandr J, Zdeněk P, Pavel Z, Ladislav N, Jan TÍ, Petr K, Martin T. Raman microspectroscopy of individual algal cells: sensing unsaturation of storage lipids in vivo. Sensors. 2010;10:8635-51.

30. Li J, Han D, Wang D, Ning K, Jia J, Wei L, Jing X, Huang S, Chen J, Li Y. Choreography of transcriptomes and lipidomes of Nannochloropsis reveals the mechanisms of oil synthesis in microalgae. Plant Cell. 2014;26:1645-65.
31. Paszek P, Ryan S, Ashall L, Sillitoe K, Harper CV, Spiller DG, Rand DA, White MR. Population robustness arising from cellular heterogeneity. Proc Natl Acad Sci USA. 2010;107:11644.

32. Lidstrom ME, Konopka MC. The role of physiological heterogeneity in microbial population behavior. Nat Chem Biol. 2010;6:705-12.

33. Müller S, Harms H, Bley T. Origin and analysis of microbial population heterogeneity in bioprocesses. Curr Opin Biotech. 2010;21:100-13.

34. Delvigne F, Goffin P. Microbial heterogeneity affects bioprocess robustness: dynamic single-cell analysis contributes to understanding of microbial populations. Biotechnol J. 2014;9:61-72.

35. Schie I, Kiselev R, Krafft C, Popp J. Rapid acquisition of mean Raman spectra from eukaryotic cells for a robust single cell classification. Analyst. 2016;141:6387-95.

36. Schie IW, Chan JW. Estimation of spectra sample size for characterizing single cells using micro-Raman spectroscopy. J Raman Spectrosc. 2016:47:384-90.

37. Wang $Y$, Song $Y$, Tao $Y$, Muhamadali $H$, Goodacre R, Zhou N-Y, Preston GM, $\mathrm{Xu}$ J, Huang WE. Reverse and multiple stable isotope probing to study bacterial metabolism and interactions at the single cell level. Anal Chem. 2016:88:9443-50

38. Vinay KBN, Guo S, Bocklitz TW, Roesch P, Popp J. Demonstration of carbon catabolite repression in naphthalene degrading soil bacteria via Raman spectroscopy based stable isotope probing. Anal Chem. 2016;88:7574-82.

39. Berry D, Mader E, Lee TK, Woebken D, Wang Y, Zhu D, Palatinszky M, Schintlmeister A, Schmid MC, Hanson BT. Tracking heavy water (D2O) incorporation for identifying and sorting active microbial cells. Proc Natl Acad Sci USA. 2014;112:E194-203.

40. Tao Y, Wang Y, Huang S, Zhu P, Huang WE, Ling JQ, Xu J. Metabolic-activity based assessment of antimicrobial effects by D2O-labeled single-cell Raman microspectroscopy. Anal Chem. 2017;89:4108-15.

41. Li M, Huang WE, Gibson CM, Fowler PW, Jousset A. Stable isotope probing and Raman spectroscopy for monitoring carbon flow in a food chain and revealing metabolic pathway. Anal Chem. 2013;85:1642-9.

42. Zhang $P$, Ren $L$, Zhang $X$, Shan $Y$, Wang $Y$, Ji Y, Yin H, Huang WE, XU J, Ma B. Raman-activated cell sorting based on dielectrophoretic single-cell trap and release. Anal Chem. 2015:87:2282-9.

43. Huang WE, Ward AD, Whiteley AS. Raman tweezers sorting of single microbial cells. Environ Microbiol Rep. 2009;1:44-9.

44. Wang Y, Ji Y, Wharfe ES, Meadows RS, March P, Goodacre R, Xu J, Huang WE. Raman activated cell ejection for isolation of single cells. Anal Chem. 2013:85:10697-701

45. Zhang Q, Zhang P, Gou H, Mou C, Huang WE, Yang M, Xu J, Ma B. Towards high-throughput microfluidic Raman-activated cell sorting. Analyst. 2015;140:6163-74.

46. Stöckel S, Meisel S, Elschner M, Rösch P, Popp J. Identification of Bacillus anthracis via Raman spectroscopy and chemometric approaches. Anal Chem. 2012;84:9873-80.

47. Almeida MR, Alves RS, Nascimbem LB, Stephani R, Poppi RJ, de Oliveira LFC. Determination of amylose content in starch using Raman spectroscopy and multivariate calibration analysis. Anal Bioanal Chem. 2010;397:2693-701.

\section{Submit your next manuscript to BioMed Central and we will help you at every step:}

- We accept pre-submission inquiries

- Our selector tool helps you to find the most relevant journal

- We provide round the clock customer support

- Convenient online submission

- Thorough peer review

- Inclusion in PubMed and all major indexing services

- Maximum visibility for your research

Submit your manuscript at www.biomedcentral.com/submit 